Illinois State University

ISU ReD: Research and eData

Theses and Dissertations

9-19-2014

\title{
What Kills Love? Factors Influencing the Ending of Love in Romantic Relationships
}

Michelle Duda

Illinois State University, mlduda@ilstu.edu

Follow this and additional works at: https://ir.library.illinoisstate.edu/etd

Part of the Clinical Psychology Commons, and the Counseling Psychology Commons

\section{Recommended Citation}

Duda, Michelle, "What Kills Love? Factors Influencing the Ending of Love in Romantic Relationships" (2014). Theses and Dissertations. 255.

https://ir.library.illinoisstate.edu/etd/255

This Thesis is brought to you for free and open access by ISU ReD: Research and eData. It has been accepted for inclusion in Theses and Dissertations by an authorized administrator of ISU ReD: Research and eData. For more information, please contact ISUReD@ilstu.edu. 


\title{
WHAT KILLS LOVE? FACTORS INFLUENCING THE ENDING OF LOVE IN ROMANTIC RELATIONSHIPS
}

\author{
Michelle L. Duda
}

101 Pages

December 2014

This thesis reports the results of an online survey study that examined dimensions of love, positive behaviors, negative behaviors, and relationship satisfaction in current romantic relationships where the individual currently had a feeling of being in love with their partner ("still in love" or SIL group) versus in past romantic relationships where the individual once had a feeling of being in love with that person, but ceased loving essentially, fell out of love with - that person over the course of the relationship ("fell out of love" or FOL group). An MTurk sample of 202 individuals (Mean age $=35.25$ ) completed an online survey assessing the variables of the study. The results supported the hypothesis that participants in the FOL group would report significantly lower levels of each of the dimensions of love than participants in the SIL group. The results also supported the hypothesis that participants in the FOL group would report experiencing significantly more of the problem behaviors from their partners than would participants in the SIL group. The third hypothesis, which stated that participants in the FOL group would support a statement regarding a negative change in the perception of their partner during the course of the relationship to a significantly greater degree than the SIL group, was also supported by the results. Additional analyses found which dimensions of love 
and behavioral violations of love were the strongest variables to distinguish between those in the SIL group and those in the FOL group and which factors were most important in the SIL group to predict relationship satisfaction. 
WHAT KILLS LOVE? FACTORS INFLUENCING THE ENDING OF LOVE IN ROMANTIC RELATIONSHIPS

MICHELLE L. DUDA

A Thesis Submitted in Partial Fulfillment of the Requirements for the Degree of

MASTER OF SCIENCE

Department of Psychology

ILLINOIS STATE UNIVERSITY 
(C) 2014 Michelle L. Duda 
WHAT KILLS LOVE? FACTORS INFLUENCING THE ENDING OF LOVE IN ROMANTIC RELATIONSHIPS

MICHELLE L. DUDA

COMMITTEE MEMBERS:

Raymond M. Bergner, Chair

Susan K. Sprecher 


\section{ACKNOWLEDGMENTS}

I would like to thank my committee, Drs. Raymond M. Bergner and Susan K. Sprecher for their guidance and support throughout this process, as well as all the time they dedicated to reading drafts. Without them, this process would have been extremely difficult. I would also like to thank two very supportive colleagues, Andy Eichler and Jennifer Yeoward, for their continuous help in this process. Finally, I would like to thank my family for continuing to believe in me and for always supporting me throughout my educational career.

M.L.D. 


\section{CONTENTS}

Page

ACKNOWLEDGMENTS

CONTENTS

TABLES

\section{CHAPTER}

I. INTRODUCTION 1

Purpose of the Proposed Study 2

II. REVIEW OF THE LITERATURE $\quad 4$

Formulation of Love in this Research 5

$\begin{array}{ll}\text { Other Definitions of Love } & 7\end{array}$

Love as a Prototype $\quad 8$

Love as Communal Responsiveness $\quad 10$

Taxonomy of Loves 12

Research on Factors Involved in Maintaining Love 14

Maintenance Behaviors $\quad 14$

Conflict Resolution 16

Correlates of Long-Term Love 16

Conformity to Prototype Features 18

"What Makes Love Last?" 19

Research on Factors Involved in Losing Love 20

Problematic Conflict Styles $\quad 20$

The "Four Horsemen" 21 
The first horsemen: Criticism.

The second horsemen: Contempt.

The third horsemen: Defensiveness.

The fourth horsemen: Stonewalling.

Different Forms of Abuse

Deception

Infidelity

Substance Use

The Present Study's Purpose and Hypotheses

III. METHOD

Participants

Measures

Demographic Information

Factors in Intimate Relationships (FIR)

Questionnaire

Relationship Assessment Scale (RAS)

Procedure

IV. ANALYSIS OF THE DATA 41

Results of Data Analysis for Hypotheses 41

Results of Data Analysis for Exploratory Questions 46

$\begin{array}{ll}\text { V. DISCUSSION } & 52\end{array}$

Summary of Study $\quad 52$

Interesting and Unexpected Findings $\quad 60$

Strengths, Limitations, and Future Research Ideas 62

Conclusions 


\section{TABLES}

Table $\quad$ Page

1. Descriptive Statistics and Univariate Effect Sizes for Self Ratings on Love Dimensions in SIL and FOL Groups

2. Descriptive Statistics and Univariate Effect Sizes for Partner Ratings (by the Individual) on Love Dimensions in SIL and FOL Groups

3. Descriptive Statistics for Occurrence of Violation Behaviors in SIL and FOL Groups

4. Canonical Discriminant Function Correlations

5. Linear Stepwise Regression Predicting Satisfaction for SIL Group 


\section{CHAPTER I}

\section{INTRODUCTION}

What kills love? The question is an important one. The Centers for Disease Control and Prevention (CDC) keeps records of probability rates of first marriages ending within 10 years among women ages 15 to 44. In 1995, this organization reported a 33\% probability of first marriages ending (through separation, divorce, or annulment). This percentage jumped to $36 \%$ in 2002, and then decreased to $32 \%$ from 2006 to 2010 . Thus, while this does not provide a direct measure of love per se, the suggestion here is that love relationships continue to fail at an alarming rate. The ending of a romantic relationship often has serious negative impacts on people. These impacts include psychological or emotional problems, financial problems, legal problems, and problems with family (Beste, Bergner, \& Nauta, 2003). Combining these severe negative effects with the prevalent failure rate of romantic relationships makes it clear that it is important to attempt to identify factors that influence the cessation of love in romantic relationships.

Prior research has worked to identify a number of different kinds of factors that are relevant to the question of what causes love to cease. Described in detail in the next chapter, these include studies of factors such as (a) "maintenance behaviors" (i.e., behaviors that tend to keep the relationship satisfying, stable, and lasting); (b) destructive and constructive conflict behaviors; (c) relationship characteristics empirically associated with relationship longevity (e.g., sexual frequency) and with relationship satisfaction 
(e.g., use of pornography); (d) factors having to do with violating love relationships (e.g., sexual and/or emotional infidelity; various kinds of abuse); and more.

However, although there has been a large amount of research that has focused on factors associated with the longevity of romantic relationships and factors associated with break ups, very little research has focused on factors that are explicitly associated with remaining in love with a person versus factors that are associated with ceasing loving a person. This is a particularly important area of research because it would be extremely helpful to understand what goes into maintaining and ending the emotional connection of love in romantic relationships.

\section{Purpose of the Proposed Study}

The present research replicated and extended Beste et al.'s (2003) study on what keeps love alive. This study addressed a somewhat different question, that of what kills love. That is, I sought to identify relationship patterns, behaviors, and omissions that are influential in causing someone who loves another to cease loving that other. This research extended Beste et al. (2003) by including a measure of relationship satisfaction in order to explore how the responses to the items on relationship patterns, behaviors, and omissions may correlate with relationship satisfaction.

In this thesis, the following topics will be presented in this order. First, to define what was meant by "love" in this study, a formulation of this concept derived from previous research will be presented. Second, research relevant to the topic of what maintains and what damages love will be reviewed. Third, the hypotheses for this study regarding different factors that were predicted to identify partners who ceased loving one another versus those who remained in love will be explained. Fourth, the methodological 
procedures and measures used in this research will be described. Fifth, the analysis of the data and results will be described. Finally, the interpretation of the results will be provided, limitations will be presented, and will end with final concluding remarks. 


\section{CHAPTER II}

\section{REVIEW OF THE LITERATURE}

This chapter will outline five main topics. First, information will be presented on the formulation of romantic love that was used in this research as well as research that supports this formulation of romantic love. Second, research will be presented on three other formulations of love that are similar to the formulation that was used in this research. Third, information will be presented on factors that research has found to be important to the maintenance of love in romantic relationships. This will include research on (a) maintenance factors in intimate relationships, (b) important communication patterns, such as conflict resolution in romantic relationships, (c) correlates of long-term romantic relationships, (d) conformity to the prototype characteristics of love, and (e) key relationship dimensions and behaviors. Fourth, information will be presented on factors that research has found to influence losing love in romantic relationships. This will include research on (a) problematic conflict styles in romantic relationships, (b) the "four horsemen," from Gottman (2012), (c) different forms of abuse in romantic relationships, (d) the presence of deception/lying in romantic relationships, (e) different forms of infidelity that may occur in romantic relationships, (f) the impact of substance usage on romantic relationships, and $(\mathrm{g})$ the effects of pornography usage on romantic relationships. 


\section{Formulation of Love in this Research}

The formulation of romantic love employed in this thesis comes from research done by Roberts (1982, 1985), Davis (1985), Davis and Todd (1982), Bretscher and Bergner (1991), Bergner (2000), Beste, Bergner, and Nauta (2003), and Hegi and Bergner (2010), in which prototypical characteristics that make up romantic love were articulated and examined in various ways. This formulation is the latest version of a series beginning with the work of Davis and Todd (1982) and subsequently refined in a series of studies, the latest being Hegi and Bergner (2010). The 10 prototypical aspects of romantic relationships emerging from this research are the following:

- Investment in the well-being of the beloved (IWB). The person is concerned for their partner's well-being for their partner's own sake, not for how the other's well-being would benefit them. The person views their partner's needs as important even if their needs do not satisfy their own. This characteristic is viewed as the most critical by Bergner (2000) and was strongly endorsed by participants as essential to love in later research (Bergner et al., 2013; Hegi \& Bergner, 2010).

- Appreciation. The person admires their significant other for who they are; they do not wish their partner to be another person; they take their partner seriously. Such appreciation usually takes the form of idealization at first, but wanes over time into a less idealized acceptance and admiration for their partner.

- Sexual desire. The partners want to experience physical intimacy with one another; this includes touching, holding, and making love. 
- Intimacy. The partners want to be with one another in a close and intimate way; they do not want to experience physical/emotional distance from each other.

- Commitment. The partners are committed to be with one another for the long term, through good and bad times, "til death do us part."

- Exclusivity. The person sees their partner as their "one and only."

- Understanding. Partners understand each other's world-view, goals, and values; they know the true person, and not an inaccurate perception of them.

- Authenticity. Partners are authentic in their love relationships. The relationship involves genuine relating so neither partner is playing a role or hiding who they actually are.

- Trust. Partners feel that they can count on one another not to betray or violate their relationship. They feel, for example, that their significant other will be sexually faithful and will keep intimate personal information private and not reveal it to others.

- Enjoyment. Partners enjoy being around one another and spending time together. Although there may be disagreements or times of boredom, the partners overall have enjoyable experiences together.

Empirical support for the importance of all of these dimensions, as well as for the essentialness of certain of them, in romantic relationships, was found in research by Bergner et al. (2013) and by Hegi and Bergner (2010). Further, the above listing of relationship characteristics overlaps considerably with the currently prevalent approach to developing prototypes of love relationships such as romantic and companionate love (Aron, Fisher, \& Strong, 2006; Fehr, 2006). However, unlike prototypical formulations in 
which nothing is regarded as essential to love, Bergner et al. (2013) and Hegi and Bergner (2010) found that certain characteristics are judged by research participants to be necessary for them to judge that one person loves another person; if these characteristics are missing, they judge that person A does not love person B at all. Their studies found that foremost among these was the characteristic "investment in the well-being of the partner" (IWB). This investment involves partners being invested in and acting on behalf of their partner's needs, goals, and more for the partner's own sake.

In previous research, IWB has been discussed and defined in a variety of ways. Singer (1984), in a classic 3-volume study of the history of love in Western cultures, stated that IWB involves placing importance on the needs of their partner for their partner's sake and not for the sake of how it would benefit their own needs. Although relationships always include some element of self-interest, in a love relationship, the interest in the partner would not be entirely narcissistic. In other previous research by Fehr (2006), a factor very similar to IWB, companionate love, was defined as a type of love, but not as a characteristic. Sprecher and Fehr (2005), however, feature something very much like this altruistic element in their characterization of compassionate love. Hegi and Bergner (2010) focused on IWB as a characteristic of love that may transcend many different types of human love.

\section{Other Definitions of Love}

This thesis is not about the nature of love. It involved picking a credible, research-supported formulation of love and then moving on to the main business of investigating what makes such love last and what damages it. However, in this section, I will briefly present past research that is concerned with the question of what love is. In it, 
I will describe three other formulations of love developed by other researchers, all of which have similarities and overlaps with the conception employed in the present research. The first formulation of love that will be described in this section will be love as a prototype (e.g., Fehr, 1988; Rosch, 1973a, 1973b). The second will be love based on communal responsiveness (e.g., Clark \& Monin, 2006). The third and final approach presents a taxonomy of different kinds of love (e.g., Berscheid, 2006; Kelly, 1983, 2002).

\section{Love as a Prototype}

One area of research on love that has been found to be consistent with the previously mentioned formulation that was used in the present research explores love as a prototype. Rosch (1973a, 1973b) believed that many language concepts could not be captured by simple definitions. She suggested that these concepts could best be recognized by their clearest examples, called prototypes. Rosch believed that cases could ordered by rank based on their level of similarity to the prototypical cases. Using this line of reasoning, Fehr (1988) studied whether the concept of love could be better captured with a prototype than with a definition. The participants in her study were asked to list characteristics and features of the concept of love. This sample included college students and after they listed characteristics, they were asked to rate the characteristics by prototypicality (goodness-of-example). They rated the characteristics of companionate love (i.e., caring, trust, intimacy) as more central to the concept of love than characteristics of passionate love (i.e., sexual passion, gazing at the other). Researchers have also compared populations in different regions of North America on their prototype ratings of love (Button \& Collier, 1991; Fehr, 1988; Fehr, 1993; Luby \& Aron, 1990). In all of these studies, the characteristics that had the highest prototypicality rating across 
these population regions were trust, caring, honesty, friendship, and respect (Fehr, 1993). There is consensus, at least in North American populations, that the companionate features of love are most central to how the people in these regions define the concept of love.

Prototype-based research has also explored individual differences in how the prototype of love may be viewed. Previous research has found men to hold a more passionate view of love and women a more companionate view (Dion \& Dion, 1993; Fehr \& Broughton, 2001; Sprecher \& Metts, 1989). Fehr and Broughton (2001) conducted multiple within-gender analysis studies with men and women and found that both men and women held a more companionate view of love than a passionate view of love and also found that the sexes appeared to have much greater agreement than disagreement. Even though there have been some individual differences found in conceptions of love (i.e., differences related to personality characteristics, gender, and culture), the most compelling finding is the degree of similarity on the prototype of love.

The prototype approach used in these studies has been used to investigate a variety of other topics. Fehr (1988) conducted two studies that found that the prototypical features of love were more salient in memory than were the non-prototypical features. The number of studies that repeated this same finding supported the hypothesis that love would be better thought of as a prototype than a simple definition (Fehr \& Russell, 1991). Overall, thinking of love as a prototype provides extremely detailed information about the content of love. However, there are still a lot of gaps in research on how the prototype analysis can be applied to different types of love other than passionate and companionate. 


\section{Love as Communal Responsiveness}

Another area of research that provides a conception of love focuses on viewing love in terms of a couple being concerned about one other in a way very similar to that of investment in the well-being of the other. Clark and Monin (2006) termed this conception "communal responsiveness". In relationships that have communal responsiveness, partners are concerned about the other's well-being and needs. They also typically feel certain that their partner feels the same way and would do the same for them, leading them both to feel safe and comfortable in their relationship (Clark \& Monin, 2006). Communal responsiveness can show in many behaviors including a person providing benefits to their partner, attempting to fulfill their partner's needs, helping their partner with something, supporting their partner as their partner works towards a goal, combining forces to experience an enjoyable activity, caring behaviors when their partner is experiencing trouble, or showing symbols of affection towards their partner (i.e., hug, kiss, a card, flowers). Of particular relevance to the present research, the presence of communal responsiveness has been found to be characteristic of strong, loving relationships (Clark \& Monin, 2006). Other research on communal responsiveness has found that people in relationships need to be open with their partners about needs, goals, wants, and what they enjoy so that their partners would be able to respond appropriately (Reis \& Patrick, 1996). This is crucial so that the partner can understand, validate, and respond communally - processes that have been found to be necessary to form intimacy with another person (Reis \& Shaver, 1988).

Communal responsiveness actions provide partners with support and a strong sense of security (Clark \& Monin, 2006). This sense of security has been found to allow a 
partner to relax, achieve, and enjoy other things, because they feel secure knowing that someone beside themselves is concerned with their well-being (Mikulincer, Shaver, Gillath, \& Nitzberg, 2005). Mikulincer et al. (2005) found that in order for acts of communal responsiveness to provide feelings of safety and security they need to be noncontingent. This means that when an individual engages in these acts of communal responsiveness, it should be without an expectation of being rewarded or repaid by their partner.

A critical factor in relationships that tends to be responsible for promoting communal responsiveness is trust. Trust in a partner is absolutely necessary in order to create a loving relationship. This trust would include trusting that a partner truly cares about one's welfare and trusting that a partner wants to accept and be the recipient of one's care (Holmes, 2002; Holmes \& Rempel, 1989). A person who is still responsive to their partner's needs or wants even when they conflict with the needs or wants of the self typically engenders these types of trust in the other. Clark and Monin (2006) view low trust in a relationship as a main factor that prevents communal responsiveness from developing. When there is mistrust in a relationship, the person's focus becomes on selfprotection, which hinders development of the relationship (Collins, 1996; Collins \& Allard, 2001).

In sum, Clark and Monin (2006) believe that consistent giving and receiving of communal responsiveness leads to loving relationships. This communal responsiveness requires acceptance on behalf of both partners. In mutual communal relationships, this responsiveness depends on the partner's trusting that the other cares and also will accept their care. The focus on communal responsiveness is very consistent with that of 
investment in the well-being of the other (IWB) in the formulation used in my study. IWB and communal responsiveness both involve caring about another's well-being, wants, and needs, regardless of how these may benefit the self. They both also involve an understanding that both partners in the relationship would show this towards each other.

\section{Taxonomy of Loves}

A taxonomy of love carries an assumption that each type of love is different from the others in some aspect. Kelly $(1983,2002)$ argues that love is not a single phenomenon, but many phenomena. All of these phenomena are referred to as love, but are actually each a particular variety of love that includes different aspects than the other types. There are many taxonomies of love that attempt to classify the distinct varieties of love and how they are different from one another.

Berscheid $(2006,2010)$ introduced a taxonomy of love that includes types of love that have been investigated by many researchers; each type has been given a number of different names in the varying taxonomies of love. The first type of love in Berscheid's taxonomy is termed attachment love. Bowlby (e.g., 1979) and Harlow (e.g., 1958) both expressed the notion that humans have an innate system that, in response to feeling threatened, will lead them to form an attachment to a familiar person who has provided protection and comfort. The term "attachment love" can be defined as a strong affectional bond to a person. The individual will seek their attachment figure when experiencing threat and will experience distress when they are separated from this figure. As individuals grow older, their parents may or may not continue to be attachment figures to that person, but many other people can become attachment figures as well (Berscheid, 
2010). These new figures can include close friends, long-term sexual partners, and mentors.

The second type of love included in Berscheid's $(2006,2010)$ taxonomy is termed compassionate love. This type of love involves having concerns for another's welfare and engaging in behaviors to promote that other person's welfare, regardless of whether those behaviors benefit the self in any way. In other taxonomies, this love has been called "selfless love," "caregiving love," "true love," "altruistic love," and, in the formulation used in this research, "investment in the well-being of the beloved for his or her own sake.” There has been a recent increase in interest on caregiving in relationships due to caregiving being important in relationship stability and relationship satisfaction (e.g., Pasch \& Bradbury, 1998).

The third type of love included in Berscheid's $(2006,2010)$ taxonomy is termed companionate love. This type of love is included in virtually all taxonomies of love in some fashion. It has been called "friendship love," "conjugal love," "affection," and "strong liking." Causally, people tend to like people who are familiar to them (as opposed to unfamiliar), who are similar to them (as opposed to dissimilar), who like them (as opposed to dislike), and whom they find physically attractive (as opposed to unattractive) (Berscheid \& Regan, 2005). Once the causal factors of liking occur, individuals continue to attempt to maintain close proximity with people that they like and will try to behave in certain ways that the people they like will find rewarding so they continue to interact.

The final type of love in Berscheid's $(2006,2010)$ taxonomy is romantic love. This type of love is included in the large majority of other taxonomies of love and has been called "passionate love," "erotic love," "addictive love," and "obsessive love." This 
type of love is the one commonly associated with being "in love" (as opposed to just "love" in general). Many researchers have worked to find the distinctions between romantic love and companionate love (e.g., Berscheid \& Walster, 1974; Fehr, 1994; Hatfield, 1988; Hendrick \& Hendrick, 1986; Regan, 1998). These studies have all helped to clarify the differences between romantic and companionate love. The main conclusions are that: romantic love consists of an important combination of liking the individual as well as showing sexual desire towards that individual; companionate love consists of liking the individual without having sexual desire towards that individual. In addition, lust has been classified as showing sexual desire towards an individual without liking that individual.

\section{Research on Factors Involved in Maintaining Love}

This section will describe different factors found in previous research that have been found to influence the maintenance of romantic relationships. This includes research on maintenance behaviors, communication patterns (e.g., conflict resolution), factors that correlate with long-term love relationships, and key dimensions and behaviors that have been linked to romantic relationships.

\section{Maintenance Behaviors}

In close and intimate relationships, theorists have proposed that there are factors that work to push individuals together and other factors that work to pull individuals apart (Davis, 1973). If romantic relationships are not attended to, these relationships will begin to weaken. In order to work against these factors that attempt to pull individuals apart, people in relationships must engage in actions that work to maintain their relationship (Canary \& Stafford, 1994). These actions work to decrease potential alternatives to the 
relationship, increase barriers to avoid break up, and increase rewards in the relationship (Levinger, 1965). All of these actions that attempt to continue a relationship are termed maintenance behaviors. There are multiple definitions of relationship maintenance, but the most commonly used definition defines it as the stability and continuation of a relationship at a satisfying level (Dindia, 2000).

Research suggests different types of maintenance behaviors that are of particular importance. Stafford and Canary's (1991) typology categorized these behaviors into five main types: positivity, openness, assurances, networks, and sharing tasks (Canary \& Stafford, 1992, 1994; Stafford \& Canary, 1991). The first category, positivity, refers to attempts to keep interactions positive and cheerful. Specific behaviors include items such as, "I buy him/her little surprises," and "I tell jokes and try to make him/her laugh" (Dainton \& Stafford, 1993). The second category, openness, refers to self-disclosure, meta-relationship communication, advice, and empathic behaviors. Specific behaviors include items such as, "I open up about my feelings," "We discuss problems we might be having," "I rely on him/her for advice," and "I listen to him/her and try not to judge" (Dainton \& Stafford, 1993). The third category, assurances, refers to reassuring the partner about the future of the relationship and emphasizing commitment. Specific behaviors include items such as, "I say I love you," "I show him/her how much s/he means to me," and "We plan our wedding" (Dainton \& Stafford, 1993). The fourth category, networks, refers to relying on the love and support of common family and friends. Specific behaviors include items such as, "I go to his/her parents' house for the holidays," and "We play cards with our friends every week" (Dainton \& Stafford, 1993). The fifth category, sharing tasks, refers to partners jointly completing tasks. Specific 
behaviors include items such as, "I provide financial support," and "I cook dinner" (Dainton \& Stafford, 1993). Overall, these factors have been found to be associated with the maintenance of relationship satisfaction (Canary \& Stafford, 1994).

\section{Conflict Resolution}

Another area of research that has focused on factors that maintain romantic relationships has been the role of communication patterns, particularly related to communication in conflict resolution. Many studies have concluded that effective conflict resolution techniques are crucial in maintaining relationship satisfaction (Barry, 1970; Patterson, Weiss, \& Hops, 1976; Raush, Barry, Hertel, \& Swain, 1974; Scanzoni, 1965). There is further evidence that distressed couples have more problems that go unresolved and have more episodes of conflict than do nondistressed couples (Birchler \& Webb, 1977). Some literature related to conflict resolution has hypothesized that if a couple has greater reciprocal negative communication exchanges and less reciprocal positive communication exchanges they are more likely to be distressed (Azrin, Naster, \& Jones, 1973; Lederer \& Jackson, 1968; Stuart, 1969). Billings (1979) studied communication interactions between distressed married couples and non-distressed married couples while they engaged in conflict resolution tasks. This study found that distressed couples engaged in significantly more negative and fewer positive problem-solving interactions. The distressed couples also engaged in a higher number of reciprocal negative communication interactions than non-distressed couples did.

\section{Correlates of Long-Term Love}

Many researchers have explored whether long-term love relationships can truly exist and, if so, what factors are important in the maintenance of these types of 
relationships. These factors can be influential in understanding what factors are associated with what keeps love alive in relationships. Acevedo and Aron (2009) conducted a meta-analysis exploring whether long-term relationships led to the decline of romantic love. The main aspects of love that the study investigated were engagement, sexual interest, and intensity. This meta-analysis found that romantic love does exist in some long-term relationships. This romantic love usually occurs without the obsession component that is usually found in the beginning stages of love relationships. Acevedo and Aron (2009) found romantic love that existed in long-term relationships to be associated with well-being, relationship satisfaction, and self-esteem. O'Leary, Acevedo, Aron, Huddy, and Mashek (2012) focused on certain variables that they predicted would be related to intense love. They used the model founded by Acevedo and Aron (2009) that states that intense romantic love involves intensity, physical desire, and engagement, but not obsession. They also incorporated the "self-expansion" model, which states that romantic love is strengthened when partners engage in new and challenging activities with one another (Aron \& Aron, 1986).

O'Leary et al. (2012) included the following variables in their study: physical desire (i.e., affection and sexual behaviors), engagement (i.e., having positive thoughts about doing things with the partner), obsession, general life happiness, and general life passion. These variables were being examined as predictors of intense love. Their study found that the two strongest predictors of being intensely in love with one's partner were how often the individual thought about the partner when they were not there and having positive thoughts about the partner. Other predictors that significantly correlated with intense love were intercourse frequency, affection, doing new things together, and 
general life happiness. A predictor that was significantly correlated with intense love for men (but not women) was knowing the whereabouts of the partner. A variable that was significantly associated with intense love for women (but not men) was getting "fired up" about issues. The measure of intense love and the measure of relationship happiness were strongly correlated with one another. O'Leary et al. (2012) created a combined measure of sexual intercourse and affection and found that measure to be related to marital satisfaction. In a second replication of this study conducted by O'Leary et al. (2012), the participants who reported being married less than 10 years rated significantly higher levels of love than any of the other groups who were married for longer periods of time. However, the average levels of love reported in the other three groups did not significantly differ from one another. In both studies, the variables found to be the strongest predictors of intense love were the presence of affectionate gestures and behaviors towards a partner (i.e., hugs and physical response), having positive thoughts about a partner, engaging in new activities with a partner, and "general life happiness" (O'Leary et al., 2012). These factors may provide information about some characteristics that may be important in maintaining love in romantic relationships.

\section{Conformity to Prototype Features}

Fehr (1988) conducted two studies that found that when participants were given descriptions of various types of relationships, those that included prototypical features were rated as more loving than relationships that did not include prototypical features. Of especial relevance to the present research, Fehr (1988) also found that when prototypical features were violated in a relationship it was considered to have a stronger negative effect on the relationship than when non-prototypical features were violated. Fehr and 
Broughton (2004) found that individuals who conceptualized love in terms of the prototype tended to report greater love/liking for their partner than those who did not conceptualize love in terms of the prototype.

\section{"What Makes Love Last?'}

Beste, Bergner, and Nauta (2003) explored the relevance of different factors to the survival or dissolution of romantic love in relationships. In research entitled "What makes love last?", they explored a wide range of these factors. They conducted research with (a) participants who were currently in romantic relationships and reported still being in love with their partner ("SIL" group), and (b) participants who reported once being in love with a previous partner but having fallen out of love with that person ("FOL" group).

Beste et al. (2003) found that the participants in the SIL group rated characteristics of love in their relationships (the same as those described at the outset of this chapter) significantly higher then participants in the FOL group. Second, they found significant differences between the SIL and FOL participants on (a) a majority of relationship characteristic violations such as secret-keeping, emotional infidelity, lack of intimate talking, and sexual infidelity; as well as (b) destructive conflict behavior such as not sticking to the issue, stonewalling, playing for a win, and defensiveness. Participants in the SIL group reported experiencing a significantly lower number of both these types of violations and these destructive conflict resolution behaviors than the FOL group. Third, very strong differences between the FOL group and the SIL group were observed with respect to the question of whether the person they were involved with turned out to be a different and far lesser person than they originally believed, with the SIL group reporting that this was much less true of their relationships. Fourth, an overall exploratory 
analysis found that almost all of the items on the scale used in this study strongly

discriminated between those who remained in love and those who ceased being in love.

Factors that were found to most strongly discriminate between SIL and FOL participants were enjoyment of the relationship, respect for their partner, and perception that the partner was not the person originally supposed, but a different and lesser person.

\section{Research on Factors Involved in Losing Love}

This section will describe different factors found in previous research that have been found to influence relationship satisfaction, the ending of romantic relationships, and the loss of love in romantic relationships. This includes research on problematic conflict behaviors and pornography usage.

\section{Problematic Conflict Styles}

Prior research has found relationship satisfaction to be negatively related to the frequency with which each partner uses destructive conflict styles (e.g., Gottman \& Krokoff, 1989; Heavey, Layne, \& Christensen, 1993). Engagement in negative styles of conflict and having different opinions have been found to be associated with dissatisfaction in a romantic relationship (e.g., Cramer, 1998). Research has also found a negative conflict style and conflict to be significantly correlated with the duration of a relationship. This means that if a couple frequently engages in negative conflict-resolving strategies, their relationship may not last as long, and more importantly, they may cease loving one another. Some common problematic conflict styles include a partner becoming defensive when a conflict arises, withdrawing from a conflict situation in an attempt to avoid dealing with a conflict, demanding a partner engages in a conflict, or pressuring their partner to change (Kurdek, 1995). 


\section{The "Four Horsemen"}

Gottman's "four horsemen" characterize four ways of interacting with a romantic partner that have, in his empirical research and clinical work, found to be highly destructive to marital relationships (Gottman, 1995). They are listed in order from what he considers least dangerous to most dangerous and consist of criticism, contempt, defensiveness, and stonewalling. According to Gottman, as each of these communication behaviors becomes more prevalent in a marriage, the partners begin to focus on the negativity in their relationship and the partners' attempts to reconcile go unnoticed. Each of these four horsemen prepares the way for the next.

The first horseman: Criticism. Gottman (1995) described the first horsemen occurring when complaints to a partner become character-degrading criticism. Whereas simple "complaining" is attacking a behavior that a person engaged in that a partner wishes were different, “criticism” involves attacking that person’s personality or character; for example, accusing a partner of having some permanent character trait, such as being untrustworthy, deceitful, selfish, and others.

The second horseman: Contempt. Gottman (1995) distinguishes criticism from contempt by emphasizing that contempt involves intent to insult and abuse a partner psychologically. Contempt can be expressed in a direct or indirect manner. Common forms of expressing contempt include insulting a partner or calling them degrading names. Another form is the use of hostile humor, where the partner uses humor in a way to intentionally humiliate their partner. A more subtle form of using contempt is the use of mockery where a partner's words or behaviors are ridiculed to show that they are not 
respected. Subtler ways of showing contempt include nonverbal communications such as rolling eyes, giving looks of disgust, and other changes in body language.

The third horseman: Defensiveness. The following are different forms of defensiveness that Gottman (1995) cites as important:

- Denying responsibility. This occurs when a partner insists that they are never to blame in any situation, regardless of any point that the partner brings up.

- Making excuses. This is when a partner illegitimately claims that some external force caused them to behave in a certain way.

- Disagreeing with negative mind reading. This involves an individual making negative assumptions about the private motives behind their partner's behavior. This usually will cause that partner to respond defensively to that negative assumption.

- Cross-complaining. This occurs when after one partner brings up a complaint that they have, the other partner responds with a complaint that they have while disregarding what their partner just said.

- Yes-butting. A yes-but statement begins in agreement with what the person brought up, but then ends in a disagreement. The disagreement is based on the partner feeling like they have a justified reason on why they did or did not do something.

- Repeating yourself. This involves a partner continuously repeating their point of view and not attempting to see the other person's side of the situation.

- Body language. This can involve many nonverbal forms of communication such as engaging in a fake smile, folding arms across the chest, and more. 
The fourth horseman: Stonewalling. Stonewalling occurs when an individual takes himself or herself out of the interaction by becoming a "stone wall" (Gottman, 1995). They may respond to statements with "Uh huh" or "Ok" without actually paying attention to what the other person is saying or they may not respond at all. Gottman (1995) stated that men are more likely than women to become stonewallers and this could possibly be due to men's more intense physiological reactions to situations (in comparison with women).

In empirical research on these behaviors and their effects, Gottman and his colleagues (Buelhlman, Gottman, \& Katz, 1992; Gottman \& Levenson, 1992) divided couples into two groups classifying how they dealt with conflict in their relationships: regulated couples and non-regulated couples. The regulated couples and non-regulated couples were discriminated by positive and negative interactional processes (Gottman, 1995). In his research, Gottman (1995) found that non-regulated couples were significantly more likely to use "the four horsemen" than regulated couples were. The couples that displayed the greatest intensity and highest frequency of conflict were termed hostile couples. Research on non-regulated couples found that they reported more severe marital problems, lower marital satisfaction, and were at a greater risk for marital dissolution (separation or divorce) (Gottman \& Levenson, 1992). In sum, these problematic conflict behaviors can have a significant impact on romantic relationships. The present study will observe the occurrence of these conflict behaviors in romantic relationships and will see how they may influence the cessation of love in the relationships. 


\section{Different Forms of Abuse}

Prior research has investigated the role that physical abuse, psychological/emotional abuse, and sexual abuse play in romantic relationships. Prior research has found a negative relationship between psychological abuse and relationship satisfaction (e.g., Falconier \& Epstein, 2010; Kim, Laurent, Capaldi, \& Feingold, 2008). However, the research examining psychological abuse and relationship satisfaction usually are cross-sectional or based on only one partner's ratings. Prior research has found physical abuse to have detrimental effects on ratings of relationship satisfaction (e.g., Lawrence \& Bradbury, 2007; O’Leary, Barling, Arias, Rosenbaum, Malone, \& Tyree, 1989). These prior studies show that individuals who were victims of physical abuse reported lower marital satisfaction scores than individuals who were never victims of physical abuse. Lawrence and Bradbury (2001) also found that couples who were physically aggressive were almost twice as likely to experience failed marriage compared with non-aggressive couples within the first four years of marriage. Prior research has focused more on physical abuse and psychological abuse than sexual abuse. However, some research has found sexual abuse to have negative impacts on relationship satisfaction (e.g., Katz \& Myhr, 2008), while other studies have found no such relationship (e.g., Katz, Kuffel, \& Brown, 2006). Panuzio and DiLillo (2010) found that higher levels of physical, psychological, and sexual abuse were generally associated with lower victim marital satisfaction at all time points in their longitudinal study. These different forms of abuse have been shown to have an impact on ratings of relationship satisfaction. In the present study, these forms of abuse will be explored as potential factors that could lead to the loss of love in romantic relationships. 


\section{Deception}

The effects that deception/lying has on romantic relationships have also been studied in prior research. Cole (2001) explored the use of deception in romantic relationships and related it to different relationship outcomes. His study found that if a person believed their partner engaged in deception, it was related to lower levels of relationship satisfaction. His research also found that the use of deception was related to lower levels of commitment to the relationship. Some prior research has found that as uncertainty increases in a relationship, the relationship had a higher likelihood of ending (Knapp, 1984; Planalp \& Honeycutt, 1985). Other previously conducted research has found that the degree of negative emotional experience in response to discovering a partner's deception was positively correlated with the likelihood of termination of the relationship (McCornack \& Levine, 1990). In a romantic relationship, honest selfdisclosure is expected and is seen as an important pro-relational behavior (Miller, Mongeau, \& Sleight, 1986). The use of pro-relational behaviors has been linked to increased relationship satisfaction, investments, and commitment (Wieselquist, Rusbult, Agnew, \& Foster, 1999). If a partner engages in the use of deception, it makes sense that this would be seen as costly to the relationship and could result in decreasing levels of relationships satisfaction, investments, and commitment (McCornack \& Levine, 1990). In sum, the use of deception in relationships could potentially have negative consequences, and could possibly have an impact on the cessation of love in a romantic relationship.

\section{Infidelity}

Infidelity can be defined as "a secret emotional, romantic, or sexual involvement that violates the commitment to an exclusive relationship" (Glass, 2002, p. 489). 
Infidelity has been noted as the leading cause of divorce (e.g.. Amato \& Previti, 2003; Beitzig, 1989). Once a person learns of a partner's infidelity, the situation can lead to feelings of anger, disappointment, self-doubt, and depression (Buunk, 1995; Cano \& O'Leary, 2000). Infidelity has been reported to occur in $20-25 \%$ of marriages (e.g., Greeley, 1994; Wiederman, 1997) and 65-75\% of college students' serious romantic relationships (e.g., Shackelford, LeBlanc, \& Drass, 2000; Wiederman \& Hurd, 1999). Some prior research has focused on the role that forgiveness and attributions have played in relationship dissolution after a partner's infidelity has been discovered (e.g., Hall \& Fincham, 2006). Overall, it appears that all types of infidelity (emotional, romantic, or sexual) could influence the potential of the loss of love occurring in a romantic relationship.

\section{Substance Use}

Prior research has focused on what effects substance use has on romantic relationships. The research conducted in this area has found that in couples where one partner heavily drank or used drugs, those couples reported significantly lower relationship satisfaction compared to couples where neither partner engaged in these behaviors (e.g., Mudar, Leonard, \& Soltysinski, 2001). Other research has found that increased abstinence length in a drug-abusing partner to be positively associated with increased relationship stability and relationship satisfaction (Fals-Stewart, Birchler, \& O'Farrell, 1999). Some research has also found that couples with comparable drinking frequencies have reported higher relationship satisfaction than couples with discrepant drinking patterns (e.g., Mudar et al., 2001; Wilsnack \& Wilsnack, 1990). These findings suggest that substance use may have an impact on the dissolution of romantic 
relationships due to such use potentially having negative effects on relationship satisfaction and stability. These effects on the relationship could lead the relationships both to end and to influence a loss of love.

\section{Pornography Use}

A number of studies have investigated how a person's pornography usage affects their partner. Bergner and Bridges (2002) conducted research on the effects of men's pornography usage on their significant others by collecting and studying 100 letters that had been posted to internet message boards by girlfriends, spouses, and fiancés of men who seemed to be heavily involved in the use of pornography. These researchers reviewed the letters to identify themes in the meanings that the women attached to their partner's pornography use. They found that when this sample of women discovered their partner's pornography use, it put them into a "new world" that was traumatic, confusing, and extremely upsetting. This new world-view included three main areas: their romantic relationship, their view of themselves and their worth, and their view of their partner's character. Many women who participated in the study reported that their partner's pornography use was a form of betrayal or cheating. Some of the women reported that they believed their partner had less sexual desire for them and believed that their partner preferred the pornographic models to them. Most women who participated in the study struggled with not internalizing their partner's pornography use to influence how they viewed their own worth and value. Many of them stated that their partner's pornography use led them to feel worthless, undesirable, and inadequate. Many also reported that their partner's use of pornography led them to lose respect for their partner. Most relevant to 
the present study, this also involved loving their partner less than they did before they discovered their heavy pornography use.

Bridges, Bergner, and Hesson-McInnis (2003) conducted another study that included a broader sample of women who were recruited through internet message boards. Their study was focused on the general attitudes of women towards a partner's pornography use, and especially if highly negative interpretations of pornography use were widespread. They found that overall, the participants reported a neutral to mildly negative view of pornography. However, a significant minority reported strongly negative reactions. For example, $32 \%$ of the sample reported it negatively affected their love-making, 39\% reported that they thought their partner's pornography use had negative effects on their relationship, and $30 \%$ felt less like a sexual person and more like a sexual object when they were with their partners (Bridges et al., 2003). There was significantly more distress found in women who were married to their partner as opposed to only dating the partner (Bridges et al., 2003), suggesting that the level of commitment to the relationship may be predictive of how distressing partner's pornography use is. The women who reported the highest frequency and duration of their partner's pornography use were also most distressed by the pornography use. These results suggest that the more a woman sees her partner's pornography use as a threat to the relationship or views it as damaging the relationship, the higher the distress levels are (Bridges et al., 2003).

Other previous research has studied how cybersex addiction can affect a significant other (Schneider, Corley, \& Irons, 1998; Schneider \& Schneider, 1990). According to Schneider (2000), survey respondents reported feeling hurt, betrayed, and rejected after learning about their partner's online sexual activities. Out of the 
respondents who were separated or divorced, many indicated that their partner's cybersex addiction was a major factor that led to their separation or divorce. Many respondents also indicated that either they or their partner lost interest in sex, and some had had no sex in months or years.

In sum, pornography use can have a significant negative impact on romantic relationships. A partner's pornography use can lead to changes in how a person views their partner, how a person views themselves in the relationships, decreased relationship satisfaction, decreased interest in sex, and can eventually lead to the end of a relationship. Prior research has also found that some people report a decrease in love towards their partner after learning of their pornography usage. This information relates to my study and can be a major contributing factor in the loss of love in romantic relationships.

\section{Gottman's Position on Pornography Use}

According to Gottman (2012), there is a link between pornography use and sexual addiction. When an individual masturbates to pornography, oxytocin and vasopressin are released, which are linked to attachment. This can lead to attachment to these images instead of attachment towards a partner. According to Gottman (2012), if partners use pornography together to enhance their relationship there is not a concern; however, pornography is typically used solo and leads to the other partner feeling betrayed. The use of pornography can also have effects on emotional connection (Gottman, 2012). In pornography, the sexual activity is most often not romantic or emotional. Two individuals typically meet and have sex and no relationship evolves. If an individual continues to watch scenarios similar to this, they may expect real-life scenarios to play out in the same way (Gottman, 2012). This can lead to the person losing interest in their sex life with 
their actual partner and an emotional disconnect between them. Another concern cited by Gottman (2012) is that pornography use can potentially be a gateway into actual infidelity. The internet can be used to seek online chat-rooms and other websites, which may lead to meeting in real life and infidelity occurring.

\section{The Present Study's Purpose and Hypotheses}

The central purpose of the present study was to examine key relationship dimensions, violations of these dimensions, and how these may relate to individuals continuing or ceasing to be in love with their partners, as well as to experience relationship satisfaction. The key dimensions of a relationship included dimensions such as care for the partner's well-being, acceptance, sexual desire, trust, respect, and others. The violations of a relationship included violations such as defensiveness, physical abuse, lying, lack of intimate communication, emotional infidelity, and others. My study obtained participants who met both of the following requirements: (1) were currently in a romantic relationship of at least 6 months duration and report still being in love with this partner and (2) have also been in a previous romantic relationship of at least 6 months duration where they were once in love with this partner (but fell out of love over the course of the relationship). The importance of collecting this type of sample was to include those individuals who have maintained love towards their partner in their current relationship but have also been in a prior relationship in which they once were in love with that partner but fell out of love with that person over the course of their relationship with them. These individuals were then randomly assigned to answer the items on the survey either about their current relationship or one of their previous relationships. The responses of persons in these two conditions (current relationship or past relationship) 
were then compared on the key relationship dimensions, violations of relationship dimensions, and relationship satisfaction. The purpose of this comparison was to determine how these groups vary on how often and to what degree the key relationship dimensions are/were present in their relationship, how often and to what degree the violations of the relationship dimensions occur/occurred, and what variables best predict relationship satisfaction among the participants answering about their current relationship. This information also helped to determine which dimensions are especially important in maintaining love, which are most detrimental, and what impacts relationship satisfaction.

The present research attempted to fill a gap in the current literature in the field. Prior research has focused on finding factors that help to maintain romantic relationships and finding factors that contribute to breakups. However, very little research has focused on what helps to maintain the actual emotional connection of love versus what leads a person ceasing to love another. The present research replicated and extended Beste et al.'s (2003) study on what keeps love alive. It addressed a similar but different question, that of what kills love. This refers to attempting to identify relationship patterns, behavior, and omissions of behavior that are influential in causing someone who loves another to cease loving that other.

My hypotheses are the following:

Hypothesis 1: Participants in this study who answer the items on the survey about a prior relationship where they were once in love but "fell out of love" with that person (the "FOL" group) will report significantly lower levels of each of the dimensions of love 
than will the participants who answer the items on the survey about a current relationship where they are "still in love" with that person (the "SIL" group).

Hypothesis 2: Certain behaviors that a romantic partner might engage in represent violations of the dimensions of love previously mentioned. For example, one clear violation of the dimensions of exclusivity and trust is sexual infidelity. By way of a second example, if one partner did not support the other in a time of need, this would typically be considered a violation of the dimension investment in the well-being of the beloved. With this concept of violation in mind, the second hypothesis was as follows: When participants in this study are provided with a list of behaviors that are commonly seen as violations of the dimensions of love, participants in the FOL group will report experiencing significantly more of these (and to a higher degree) from their partners than will participants in the SIL group.

Hypothesis 3: A clinical impression supported by previous research (Beste et al., 2003 ) is that if one partner comes to believe that the other is not who they originally believed them to be, but is instead a different and lesser person, this will be strongly associated with a lessening or even cessation of love. The third hypothesis was thus as follows: Participants in this study in the FOL group will support the following statement to a significantly greater degree than participants in the SIL group: "In my relationship, I came to feel that the partner I was with was not the person I thought he or she was at the beginning of the relationship, but was instead a lesser person." (present tense used with SIL group).

Exploratory Question 1: On a more exploratory note, we examined which of the above dimensions of love, behavioral violations of love, and/or changes in the impression 
of the beloved's character, were the strongest predictors of who will cease to love another and who will remain in love.

Exploratory Question 2: Which of the above dimensions of love, behavioral violations of love, and/or changes in the impression of the beloved's character were the strongest predictors for the responses on the relationship satisfaction scale among participants who answered the items about their current love relationship? 


\section{CHAPTER III}

\section{METHOD}

\section{Participants}

The participants in this study were individuals who were signed up as workers on the Amazon Mechanical Turk website. All people browsing Human Intelligence Tasks (HITs) on MTurk were able to see an overview of the survey to decide whether or not they wished to participate. Participants in this study were required to be at least 20 years of age and be a resident of the United States. In addition, the directions required the participants to fulfill both of the following requirements: (1) currently be involved in a romantic relationship of at least six months duration in which they would describe themselves as being "still in love" with their partner; and (2) previously have been involved in a significant romantic relationship of at least six months duration in which they believed themselves to have been at one time "in love" with that partner, but for whatever reason, ceased loving or "fell out of love" with that partner. Based on Beste et al.'s (2003) research, Faul and colleagues' (2009) G*Power 3 analysis tool was used to determine that in order to obtain results with 0.9 power, a sample size of 242 was optimal for this study.

Two hundred and sixty-nine people logged into the survey, but some people closed their web browser after reading the consent screen and some participants had extensive missing data in their responses. Two hundred and two participants were 
included in the final analyses. Exclusion of participants was due to participants not answering the questions that were needed to create scores for variables included in the final analyses, participants failing to pass the two attention checks that were included in the survey ${ }^{1}$, or due to participants failing to meet the requirements of the study (e.g., age requirement, relationship length requirement). The age range of the participants was 20 to 70 years of age. The mean age of the participants was $35.25(S D=11.43)$. The sample consisted of 75 male participants (36\%) and 127 female participants (62\%). There were 37 male participants who answered the survey items about their current relationship (SIL group) and 38 male participants who answered the survey items about a past relationship (FOL group). There were 64 female participants who answered the survey items about their current relationship (SIL group) and 63 female participants who answered the survey items about a past relationship (FOL group). The participants were assigned to either answer the survey items about their current relationship or about a past relationship by answering an item inquiring if their birthday fell on an even- or odd-numbered day of the month to help ensure equal distribution. If the individual's birth date was on an evennumbered day of the month they were taken to the version of the questionnaire to answer about their current romantic relationship. If the individual's birth date was on an oddnumbered day of the month they were taken to the version of the questionnaire to answer about a past romantic relationship.

${ }^{1}$ Two attention checks were included to help identify any participants who were randomly responding to items on the questionnaire. These items simply instructed the participant to respond to the item with a specific response to ensure they were paying attention. 
In terms of ethnicity, the participants identified themselves as the following: 157 (76\%) as White/Caucasian/European American, 24 (12\%) as Black/African American/African Descent, 7 (3\%) as Asian/Asian American, 9 (4\%) as Hispanic/Latino American, $1(.5 \%)$ as Native American, $2(1 \%)$ as Multi-Racial, and $2(1 \%)$ participants did not report their ethnic identity. For the participants assigned to answer the questionnaire items about their current relationship (SIL group), the mean length of their relationship was 85.77 months or 7.15 years $(S D=9.01)$ and the median length was 50 months or 4.17 years. For the participants assigned to answer the questionnaire items about a past relationship (FOL group), the mean length of their relationship was 38.62 months or 3.22 years $(S D=4.78)$ and the median length was 20 months or 1.67 years.

\section{Measures}

\section{Demographic Information}

The participants in this study were asked to report their age, sex, race/ethnicity, and the duration of the relationship for which they answered the survey items. This information was collected so that characteristics of the sample could be reported.

\section{Factors in Intimate Relationships (FIR) Questionnaire}

A revised version of a questionnaire created by Bretscher and Bergner (1991) entitled "Factors in Intimate Relationships" (FIR) was used for my research study. There were two versions of this questionnaire used, one pertaining to current relationships and the other to past relationships, with tenses changed accordingly. The first part of the questionnaire, "Relationship Dimensions", defined, described, and gave examples of the dimensions of romantic love described above (e.g., trust, respect, acceptance, care for the partner's well-being), but in certain cases were relabeled for clarity (e.g., "Investment 
in the well-being of the beloved" was referred to as "Care for Partner's Well-being"). After the description of each dimension, the questionnaire asked the participants to rate their current or their previous romantic relationship on how well the description fit this relationship. For example, the item pertaining to Trust read as follows: "In some relationships, we have a basic sense that we can trust each other-that we can count on each other not to betray us or to violate the relationships that we have. We do not have doubts about very critical matters in our relationships (for example, our partners being sexually unfaithful, lying about significant matters, failing to keep promises, betraying confidences, or hiding important things from us)." Participants were asked to report, using two separate questions: how they perceive the relationship in this respect, and how they believe the partner perceives it. All items were rated on a 7-point Likert scale, ranging from the label of "Does Not Fit" (1) to "Fits Very Well" (7).

The second part of the FIR questionnaire, "Occurrence of Problem Behaviors", assessed the incidence of certain clinically observed behaviors that frequently violate romantic relationships. There were 23 different violations listed and described for the participants on the questionnaire. These violations pertained to behavior on the part of the participants' partners. For example, an item pertaining to violations of the Exclusiveness dimension of love, read "Emotional infidelity: partner has formed emotional attachments with members of the opposite sex that you feel were overly close and intimate." Another item pertaining to violations of the Intimacy dimension of love, read: "Lack of intimate communication: partner did not open up to you; did not share personal feelings, concerns, or other matters with you." The participants reported on a 7-point Likert scale the degree 
to which they believe each particular violation has occurred in their current or past relationship, ranging from "Never Happened" (1) to "Happened Repeatedly" (7).

At the end of the FIR, a single additional question was asked related to whether or not there was a basic change in the participant's perception of who his or her partner was as a person: "In my relationship, I came to feel that the partner I was with was not the person I thought he or she was at the beginning of the relationship, but was instead a different and lesser person." Participants rated their level of agreement with this item on a 7-point Likert scale, ranging from "I never feel (felt) this way" (1) to "I strongly feel (felt) this way" (7).

\section{Relationship Assessment Scale (RAS)}

A measure of relationship satisfaction titled the "Relationship Assessment Scale" created by Hendrick (1988) was also used in my study. This scale includes seven items about different aspects of relationship satisfaction. For example, "How well does your partner meet your needs?", "How good is your relationship compared to most?", or "How many problems are there in your relationship?". The tense was changed for those participants who were answering the items based on a past romantic relationship. This satisfaction scale was found to have good reliability, $a=.91$. This scale was not included in similar prior research and will extend the results in the field of literature on what kills love.

\section{Procedure}

The study was reviewed by Illinois State University's Institutional Review Board to gain approval for data collection to begin. Once the study was approved, the survey link was posted through a listing on Amazon's MTurk website to solicit participants in 
the study. The post provided a brief description of the study and the requirements to participate in the study. The post read as follows:

"We are conducting research assessing how different factors influence the maintenance of love or ending of love in romantic relationships.

Data on this topic is incredibly important and may provide information on specific factors that are essential for love in romantic relationships.

\section{Requirements to participate:}

1. You must be at least 20 years of age.

2. You must currently be in a romantic love relationship of at least 6 months duration and currently have a feeling of being "in love" with your partner.

3. You must have also been involved in a previous romantic relationship of at least 6 months duration in which you would describe yourself as having been at one time "in love" with that partner but lost this feeling over the course of the relationship; that is, you ceased to be in love or "fell out of love" with this person.

\section{If you do not meet the requirements listed above, we ask that you please do} not complete this survey. Participation should take no more than

30 minutes. Select the link below to complete the survey. At the end of the survey, you will receive a code to paste into the box below to receive credit for taking our survey.

Make sure to leave this window open as you complete the survey. When you are finished, you will return to this page to paste the code into the box." 
If an individual chose to participate in this study, he or she was provided with a link for the survey in the post on the MTurk website. The individual was then taken to an informed consent screen before being able to access the survey. Once the individual read the information on the informed consent screen, they were asked to agree or disagree with the consent. After the individual accepted the agreement on the informed consent page, he or she continued to complete the measures as described above. 


\section{CHAPTER IV}

\section{ANALYSIS OF THE DATA}

This chapter will provide the outcomes of the analyses that were performed on the data collected. The outcomes of the performed analyses and descriptive statistics for the variables related to the three hypotheses will be presented in writing and in Tables 1,2 , and 3. The outcomes of the analyses performed for the two research questions will be presented in writing and in Tables 4 and 5.

\section{Results of Data Analysis for Hypotheses}

Hypothesis 1. This hypothesis stated that participants in the FOL group would report significantly lower levels of each dimension of romantic love than participants in the SIL group, was tested using a multivariate analysis of variance (MANOVA). This analysis found that there was a significant overall difference across the dimensions of love between the SIL group and the FOL group, Wilk's $\lambda=.48, F(10,190)=20.45, p<.001$,

$\eta_{\mathrm{p}}{ }^{2}=.52$. For every dimension, participants in the SIL group scored higher than participants in the FOL group. Table 1 shows the means, standard deviations, and univariate effect sizes for the participants' ratings on the dimensions of love in the SIL group (participants answering about their current relationship) versus the FOL group (participants answering about a past relationship). These ratings indicated how the participants viewed their partner and the relationship. The variables with the largest 
between-group differences included enjoyment of the partner, trust, confiding in the partner, and investment in the well-being of the beloved.

Table 1

Descriptive Statistics and Univariate Effect Sizes for Self Ratings on Love Dimensions in SIL and FOL Groups

\begin{tabular}{|c|c|c|c|c|}
\hline \multirow{2}{*}{ Item } & \multicolumn{2}{|c|}{ Conditions } & \multirow{2}{*}{$\eta_{p}^{2}$} & \multirow{2}{*}{ Univariate $F$} \\
\hline & $\begin{array}{c}\text { SIL } \\
(N=103)\end{array}$ & $\begin{array}{c}\text { FOL } \\
(N=98)\end{array}$ & & \\
\hline Investment in & $6.29(1.02)$ & $4.22(1.94)$ & .31 & 90.76 \\
\hline $\begin{array}{l}\text { Well-being of } \\
\text { Other }\end{array}$ & & & & \\
\hline Exclusiveness & $6.23(1.35)$ & $4.38(2.03)$ & .23 & 58.97 \\
\hline Acceptance & $6.01(1.21)$ & 4.49 (1.75) & .21 & 51.82 \\
\hline Sexual Desire & $5.99(1.18)$ & $4.08(2.21)$ & .23 & 59.07 \\
\hline Confiding & $5.97(1.30)$ & $3.70(1.97)$ & .32 & 93.82 \\
\hline Being Yourself & $5.89(1.39)$ & $4.18(2.15)$ & .19 & 45.17 \\
\hline Trust & $5.95(1.32)$ & $3.55(2.08)$ & .33 & 96.46 \\
\hline Respect & $6.22(1.15)$ & $4.17(2.12)$ & .27 & 73.94 \\
\hline Enjoyment & $6.23(1.10)$ & $3.35(2.05)$ & .44 & 156.88 \\
\hline Understanding & $6.02(1.16)$ & $4.45(1.84)$ & .21 & 52.87 \\
\hline
\end{tabular}

Note. All $F$ values are significant at $p<.001$

As mentioned previously, Hypothesis 1 stated that participants in the FOL group reporting on the part of their partners would report significantly lower levels of each dimension of romantic love than participants in the SIL group. Table 2 shows the means, standard deviations, and univariate effect sizes in both the SIL group and the FOL group for the participants' ratings among the dimensions of love for how they believe their partner would rate the items. Participants were asked to appraise how they believed the 
partner would respond to the items asking about the dimensions of love. The participants' perception of the partner's response was tested between the SIL group and the FOL group using a multivariate analysis of variance (MANOVA). This analysis found that there again was a significant multivariate overall difference between the SIL group and the FOL group conditions on the dimensions of love, Wilk's $\lambda=.51, F(10,193)=18.81, p<$ $.001, \eta_{\mathrm{p}}{ }^{2}=.50$. For every dimension, once again, participants in the SIL group scored higher than participants in the FOL group. The variables with the largest between-group differences included enjoyment of the participant and relationship, confiding in the partner, investment in the well-being of the beloved, exclusivity of the relationship, and level of understanding between partner and participant.

Table 2

Descriptive Statistics and Univariate Effect Sizes for Partner Ratings (by the Individual) on Love Dimensions in SIL and FOL Groups

\begin{tabular}{|c|c|c|c|c|}
\hline \multirow[b]{2}{*}{ Item } & \multicolumn{2}{|c|}{ Conditions } & \multirow[b]{2}{*}{$\eta_{\mathrm{p}}^{2}$} & \multirow[b]{2}{*}{ Univariate $F$} \\
\hline & $\begin{array}{c}\text { SIL } \\
(N=103)\end{array}$ & $\begin{array}{c}\text { FOL } \\
(N=101)\end{array}$ & & \\
\hline $\begin{array}{c}\text { Investment in } \\
\text { Well-being of } \\
\text { Other }\end{array}$ & $5.96(1.41)$ & $3.79(2.02)$ & .28 & 79.65 \\
\hline Exclusiveness & $6.09(1.55)$ & $3.84(2.13)$ & .27 & 74.47 \\
\hline Acceptance & $5.95(1.26)$ & $4.12(2.03)$ & .23 & 60.13 \\
\hline Sexual Desire & $6.01(1.35)$ & $4.51(1.99)$ & .16 & 39.54 \\
\hline Confiding & $5.87(1.41)$ & $3.69(2.04)$ & .28 & 79.42 \\
\hline Being & $6.08(1.27)$ & $4.35(1.98)$ & .22 & 55.50 \\
\hline \multicolumn{5}{|l|}{ Yourself } \\
\hline Trust & $6.00(1.31)$ & $3.99(2.05)$ & .26 & 69.71 \\
\hline
\end{tabular}




$\begin{array}{ccccc}\text { Respect } & 6.07(1.25) & 4.05(2.10) & .26 & 69.57 \\ \text { Enjoyment } & 6.27(1.05) & 3.46(2.01) & .44 & 158.52 \\ \text { Understanding } & 5.86(1.43) & 3.79(1.94) & .27 & 75.63\end{array}$

Note. All $F$ values are significant at $p<.001$

Hypothesis 2. Table 3 shows the means, standard deviations, and univariate effect sizes for both SIL and FOL participants' ratings on the occurrence of behaviors representing violations of the dimensions of love listed in the tables above. Hypothesis 2, which stated that participants in the FOL group would report experiencing significantly more (and to a higher degree) violation behaviors than participants in the SIL group, was tested using a multivariate analysis of variance (MANOVA). Due to these items including potentially sensitive topics, some participants may have chosen to skip some of these items for this reason. Given the MANOVA required a 100\% completion rate on the dependent variables, 18 of the SIL participants and 19 of the FOL participants were excluded from this analysis. This analysis found that there was a significant multivariate difference between the SIL group and the FOL group conditions on the overall number of violations of the dimensions of love, Wilk's $\lambda=.56, F(22,144)=5.23, p<.001, \eta_{\mathrm{p}}{ }^{2}=$ .44. For all but two behaviors, participants in the FOL group scored higher than participants in the SIL group. The variables with the largest between-group differences included secret-keeping, emotional infidelity, lying, and lack of intimate communication. The items that asked the participants about the occurrence of physical abuse and sexual abuse in their current or past relationship were the only two items that did not have a significant difference between the SIL group and the FOL group. 
Table 3

Descriptive Statistics for Occurrence of Violation Behaviors in SIL and FOL Groups

\begin{tabular}{|c|c|c|c|c|}
\hline & & ons & & \\
\hline Item & $\begin{array}{c}\text { SIL } \\
(N=85)\end{array}$ & $\begin{array}{c}\text { FOL } \\
(N=82)\end{array}$ & $\eta_{\mathrm{p}}^{2}$ & Univariate $F$ \\
\hline Labeling & $2.22(1.57)$ & $3.12(1.97)$ & .06 & $10.66^{* *}$ \\
\hline Defensiveness & $3.40(1.73)$ & $4.66(1.58)$ & .13 & $23.98 * *$ \\
\hline Contempt & $2.19(1.59)$ & 3.85 (1.87) & .19 & $38.57 * *$ \\
\hline Stonewalling & $2.94(1.78)$ & $4.55(1.91)$ & .16 & $31.61 * *$ \\
\hline $\begin{array}{c}\text { Not Addressing } \\
\text { Issues }\end{array}$ & $3.34(1.83)$ & $4.73(1.66)$ & .14 & $26.46^{* *}$ \\
\hline False Agreement & $2.86(1.61)$ & 4.07 (1.86) & .11 & $20.40 * *$ \\
\hline $\begin{array}{l}\text { Not Sticking to } \\
\text { Issue }\end{array}$ & $3.04(1.74)$ & $4.24(1.60)$ & .12 & $21.87 * *$ \\
\hline $\begin{array}{c}\text { Playing for a } \\
\text { Win }\end{array}$ & $2.96(1.92)$ & $4.00(1.85)$ & .07 & $12.62 * *$ \\
\hline Physical Abuse & 1.35 (1.07) & $1.55(1.35)$ & .01 & 1.08 \\
\hline Sexual Abuse & $1.16(.67)$ & $1.34(.96)$ & .01 & 1.92 \\
\hline Secret Keeping & $2.45(1.62)$ & $4.60(1.78)$ & .29 & $66.81 * *$ \\
\hline Lying & $2.33(1.58)$ & $4.35(1.97)$ & .25 & $53.90 * *$ \\
\hline $\begin{array}{c}\text { Taken Advantage } \\
\text { Of }\end{array}$ & $1.86(1.60)$ & $3.11(2.18)$ & .10 & $18.01 * *$ \\
\hline $\begin{array}{c}\text { Lack of } \\
\text { Communication }\end{array}$ & $2.94(1.76)$ & $4.91(1.68)$ & .25 & $54.83 * *$ \\
\hline Pornography & $1.62(1.52)$ & $2.02(1.64)$ & .02 & 2.69 \\
\hline Drug Use & $1.67(1.39)$ & $2.56(2.18)$ & .06 & $9.95 * *$ \\
\hline Underfunctioning & $2.35(1.84)$ & $3.59(2.14)$ & .09 & $15.91 * *$ \\
\hline $\begin{array}{c}\text { Financial } \\
\text { Responsibilities }\end{array}$ & $2.32(1.95)$ & $3.30(2.22)$ & .05 & $9.35 * *$ \\
\hline Sex Frequency & $2.64(1.71)$ & $3.89(2.07)$ & .10 & $18.27 * *$ \\
\hline
\end{tabular}




$\begin{array}{ccccc}\text { Emotional } & 1.80(1.38) & 4.11(2.21) & .29 & 66.36^{* *} \\ \text { Infidelity } & 1.35(1.02) & 3.09(2.33) & .19 & 39.16^{* *} \\ \begin{array}{c}\text { Sexual Infidelity } \\ \text { Unacceptable }\end{array} & 1.28(.81) & 2.30(2.07) & .10 & 17.88^{* *} \\ \begin{array}{l}\text { Sexual Behavior } \\ \text { Note. } *=p<.05 ; * *\end{array} * p<.01 & & & \end{array}$

Hypothesis 3. This hypothesis stated that participants in the FOL group would endorse the following statement to a significantly greater degree than the participants in the SIL group: "In my relationship, I came to feel that the partner I was with was not the person I thought he or she was at the beginning of the relationship, but was instead a different and lesser person." The response options for this item ranged from $1=I$ do/did not feel this way at all to $7=$ I strongly feel/felt this way. While analyzing this hypothesis, the Kolmogorov-Smirnov test found that the scores for the perception of the partner for the SIL group $(D[104]=.32, p<.001)$, and the scores for the perception of the partner for the FOL group $(D[101]=.20, p<.001)$, significantly violated the parametric assumption of normality. Therefore, Mann-Whitney's U non-parametric test was used to test this hypothesis. This analysis found that participants in the FOL group $[M=4.83(.21), M d n=5]$ scored significantly higher than those in the SIL group $[M=$ $2.04(.16), M d n=1]$ on their ratings of the perception of the partner, $U=1729.0, z=-$ $8.54, p<.001$.

\section{Results of Data Analysis for Exploratory Questions}

The first exploratory question asked which of the dimensions of love, behavioral violations of love, and/or changes in the perception of the beloved's character, were the strongest predictors of who would cease to love another and who would remain in love. First, a multivariate analysis of variance (MANOVA) was conducted first to determine if 
there were multivariate differences between the groups. This test did find a significant overall difference between the two groups, Wilk's $\lambda=.35, \chi^{2}=164.48, p<.001$. Next, a discriminant function analysis was employed to identify what factors accounted for the differences between the groups. See Table 4 for the canonical discriminant function correlations. The specific factors found to be best discriminators of those participants in the SIL group and those participants in the FOL group were, change in perception of the partner, unacceptable sexual behavior, participant's rating of partner's enjoyment of them and the relationship, participant's ratings of partner's sexual desire, and emotional infidelity.

Table 4

Canonical Discriminant Function Correlations

Item Correlation

Your Investment in Well-being of Other .25

Your Exclusiveness .28

Partner's Sexual Desire $-.39$

Your Confiding .31

Partner's Enjoyment .40

Financial Responsibilities .29

Sex Frequency $-.21$

Emotional Infidelity $-.39$

Unacceptable Sexual Behavior

Perception of Partner $-.56$ 
The second exploratory question, which asked of the above dimensions of love, behavioral violations of love, and/or changes in the impression of the beloved's character, which would be the strongest predictors of relationship satisfaction among the SIL group, was investigated using a stepwise linear regression. The stepwise linear regression was used to predict relationship satisfaction for participants currently in loving relationships. See Table 5 for 10 stepwise models and associated predictors of satisfaction for the SIL participants. After the $10^{\text {th }}$ stepwise iteration, I found 8 variables that accounted for a significant portion of variance in satisfaction, $R^{2}=.81, F(42,41)=8.78, p<.001$. These variables included: change in perception of the partner, secret-keeping, failure to maintain financial responsibilities, emotional infidelity, respect toward partner and relationship, lack of intimate communication, underfunctioning, and disagreements about frequency of sexual behavior. Among these variables, the three strongest predictors of satisfaction for the SIL group were change in the perception of the partner, emotional infidelity (which were negatively related to relationship satisfaction), and respect toward partner (which was positively related to relationship satisfaction).

Table 5

Linear Stepwise Regression Predicting Satisfaction for SIL Group

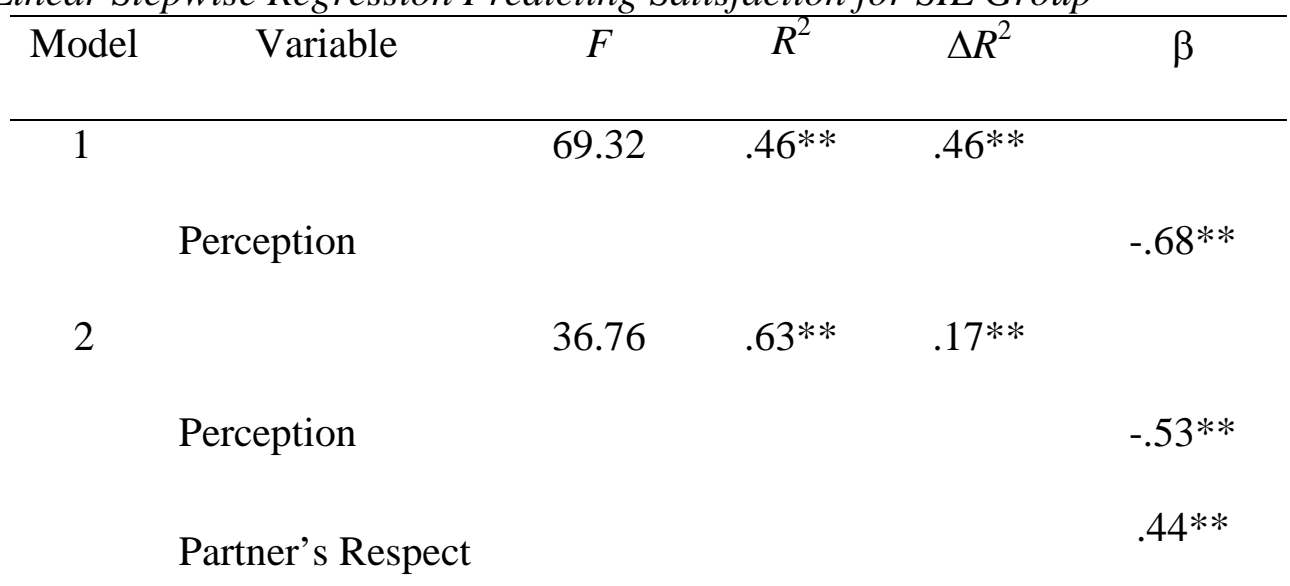


$20.55 \quad .70 * * \quad .08 * *$

Perception

Partner's Respect

Secret Keeping

4

$11.60 .74 * * \quad .04 * *$

Perception

Partner's Respect

Secret Keeping

Financial

Responsibilities

5

Perception

7.89

$.77 * *$

$.02 * *$

Partner's Respect

Secret Keeping

Financial

Responsibilities

Emotional

Infidelity

6

$5.12 \quad .78^{* *} \quad .02 *$

Perception

Partner's Respect

$-.31 * *$

.14

Secret Keeping

Financial

Responsibilities

Emotional

Infidelity

Your Respect 
$2.40 \quad .77 * * \quad-.01$

Perception $-.29 * *$

Secret Keeping

Financial

Responsibilities

Emotional

Infidelity

Your Respect

8

$\begin{array}{lll}5.26 & .79 * * & .02 *\end{array}$

Perception

Secret Keeping

Financial

Responsibilities

Emotional

Infidelity

Your Respect

Lack of

$79 *$

$-.27 * *$

$-.19 * *$

$-.18 * *$

$-.22 * *$

$.27 * *$

$-.15 * *$

9

Communication

$4.36 \quad .80^{* *} \quad .01^{*}$

Perception

Secret Keeping

Financial

Responsibilities

Emotional

Infidelity

Your Respect

Lack of

4.36

$-.26 * *$

$-.18 * *$

$-.13$

$-.22 * *$

$.28 * *$

$-.14 *$

Communication

Underfunctioning

$-.13 *$

10

$4.00 \quad .81 * * \quad .01 *$ 
Perception

$-.30 * *$

Secret Keeping

$-.17 * *$

Financial

$-.12$

Responsibilities

Emotional

$-.21 * *$

Infidelity

Your Respect

$.26 * *$

Lack of

$-.19 * *$

Communication

$-.15^{* *}$

Underfunctioning

$.12 *$

Sexual

Frequency

Note. ${ }^{*}=p<.05 ; * *=p<.0$ 


\section{CHAPTER V}

\section{DISCUSSION}

\section{Summary of Study}

The purpose of my study was to identify relationship patterns, behaviors, and omissions of certain behaviors that are influential in causing someone who loves another to cease loving that other. In simple terms, the aim was to explore the answer to the question of what kills love. For example, I examined factors such as trust, exclusivity, respect, enjoyment of partner and relationship, investment in the well-being of the beloved (IWB), emotional infidelity, contempt, secret-keeping, lying, and lack of intimate communication. Past research has focused on factors associated with the maintenance of romantic relationships (e.g., Canary \& Stafford, 1992, 1994) and factors associated with break ups (e.g., Gottman \& Krokoff, 1989; Heavey et al., 1993). However, little research has focused on factors explicitly associated with remaining in love with an individual and factors associated with falling out of love with an individual. My research sought to fill the research gap by identifying how relationship patterns, behaviors, and behavioral omissions differ between those answering about a current romantic relationship where they are still in love with their partner (SIL group) versus those who answer about a past romantic relationship where they fell out of love with the person over the course of the relationship (FOL group). 
My study replicated and extended prior research by Beste et al. (2003), which explored the question of what keeps love alive. Whereas that research explored the question of what keeps love alive in an undergraduate sample, I sought to answer the question of what kills love using a more diverse sample of adults across the United States who were both older and who came from a wider variety of backgrounds. Unlike the Beste et al. (2003) research, further, I required participants to be both currently in a loving relationship of at least 6 months and to have been in a previous relationship lasting at least 6 months where they fell out of love with that individual over the course of the relationship. These requirements were included to help avoid fundamental differences between the SIL and FOL groups, such as some participants in the FOL group being particularly difficult individuals to be in relationships with and those difficulties contributing significantly to their prior relationship ending and also to why they are not currently in a romantic relationship. The use of random assignment to either condition (i.e., reporting about their current relationship or a previous relationship) helps to ensure the participants should be similar on all other characteristics except for the manipulation to which they were assigned (to answer about a current relationship or a past relationship). Further, my study extended Beste et al. (2003) by including a satisfaction scale to see which factors were the strongest predictors of satisfaction in participants who answered about their current love relationship. Finally, my research extended Beste et al. (2003) by updating the questionnaire to include more violations of love, dimensions of love, and modernized wording in other areas of the questionnaire as well. The inclusion of these variables was important because, while conducting the literature review, these 
factors were noted as potential behaviors that have been linked to having serious positive or negative impacts on romantic relationships (e.g., Beitzig, 1989; Cole, 2001; Dainton \& Stafford, 1993). The domains that are seen as violating love included variables such as false agreement, lying, pornography use, failure to meet financial responsibilities, disagreements about sexual frequency, and lying. The dimensions of love included variables such as trust, understanding, enjoyment of the partner and relationship, exclusivity, sexual desire, and acceptance.

First, I tested if participants in the FOL group reported significantly lower levels of each of the dimensions of love than participants in the SIL group. Based on a MANOVA between the SIL group and the FOL group, I found support for this hypothesis. Beste et al. (2003) found the biggest differences between the SIL group and the FOL group on the dimensions of exclusiveness and sexual desire. The dimensions that were found to produce the largest differences between the SIL group and the FOL group differed substantially between my study and the previous one. My study found the largest differences between the SIL group and the FOL group on the dimensions of enjoyment, trust, confiding, and investment in the well-being of the beloved, with the FOL group reporting significantly lower levels on each of these variables than the SIL group. One possible explanation for these differences could be related to the differences in the samples. Beste and her colleagues' examined a younger, undergraduate sample presumably more concerned with sex and having an exclusive relationship with a partner than a sample of slightly older adults (Mean age $=35.25$ ) would be. My sample of older adults would likely be more concerned with dimensions that are more related to long- 
term, serious relationships (e.g., confiding in a partner, investment in the well-being of the partner) than younger individuals would be.

My analysis of the first hypothesis also examined ratings that the participant provided on how they believed their partners would rate the relationship on the dimensions of love. There was also support found for the first hypothesis in these ratings, with the FOL group scoring significantly lower on all of the dimensions of love than the SIL group. This information is important because it gives insight into what particular dimensions are especially critical in maintaining love in romantic relationships and also gives information on the possibility that the absence of these dimensions is particularly detrimental in romantic relationships (and potentially influential in leading to dissolution).

The findings related to the dimensions of love in my study provide support for some important theories. The Social Interdependence Theory (Johnson \& Johnson, 2005) states that interdependence is present when the accomplishment of each individual's goals is affected by the actions of others. Interdependence can be positive (e.g., cooperation) or negative (e.g., competition). In my study, having positive interdependence was evidenced by having certain dimensions of love present in a romantic relationship (e.g., IWB). The Investment Model (Rusbult, 1980, 1983) states that an individual's commitment to a relationship depends on satisfaction related to rewards and costs in the relationship, comparison to potential alternative relationships (i.e., other potential partners), and amount of investment that the individual has in the relationship. In my study, if a relationship has many of the dimensions of love present, 
this is likely to be associated with many rewards (i.e., positive aspects, benefits) that lead to the maintenance of love and continuance of the relationship.

For my second hypothesis, I predicted that participants in the FOL group would report experiencing significantly more behaviors (and to a higher degree) that represent violations of the relationship (as well as violations to the dimensions of love previously mentioned) than participants in the SIL group. I found support for this hypothesis, with the largest differences between the SIL and FOL groups on the violations of secretkeeping, emotional infidelity, and lying, with participants in the FOL group scoring significantly higher than participants in the SIL group on these dimensions. Beste et al. (2003) found the largest differences between their SIL and FOL groups on the violations of secret-keeping, emotional infidelity, and lack of intimacy, indicating strong consistency of her findings with the present ones with respect to secret-keeping and emotional infidelity. A common theme in these large difference-generating dimensions with the FOL group reporting significantly higher levels than the SIL group (e.g., secret-keeping, emotional infidelity, lack of intimacy) is that they are all forms of distancing behaviors. These types of behaviors have been found in previous research to be linked with decreased marital satisfaction and eventual marital dissolution (e.g., Pasch \& Bradbury, 1998; Roberts, 2004). Finally, with respect to the second hypothesis, I found surprisingly small (and not significant) differences between the SIL group and the FOL group on the dimension violations physical abuse, sexual abuse, and pornography use. This likely occurred due to this particular sample experiencing a low prevalence of these behaviors in their relationships. 
My third hypothesis predicted that participants in the FOL group would agree more with the statement: "In my relationship, I came to feel that the partner I was with was not the person I thought he or she was at the beginning of the relationship, but was instead a different and lesser person," than the SIL group. I found a significant difference in the ratings on this item between the SIL group and the FOL group, with participants in the FOL group agreeing significantly more with this item than the FOL group. When Beste et al. (2003) analyzed this item, they found some of the largest findings in their study: individuals in the FOL group endorsed the statement at relatively high levels, while those in the SIL group endorsed the statement at relatively low levels. These consistent results show that individuals who are currently in love with their romantic partner find their partner to be largely similar (or the same) as the person they believed them to be when they first began the relationship. The responses from the individuals who answered the questionnaire about a past romantic relationship (FOL group) show that they found that particular partner to be a different (extremely different, in some cases) and lesser person than they believed them to be at the beginning of the relationship, suggesting a dramatic decline in the level of respect experienced over the course of the relationship. If an individual finds his or her partner to not be what they originally thought, and especially less respect-worthy, the data show this to be strongly associated with a decline in the love they experience for this person. This phenomenon could occur due to one or both partners changing over the course of the relationship in some significant way (e.g., personality changes, values, priorities, opinions).

Another common phenomenon that might lead to changes in perception of a partner is a high level of initial partner idealization; i.e., the initial attribution to the 
partner of positive characteristics that may not necessarily be present, or may not be present to the degree supposed. This leads to positive illusions of the relationship. However, over time as their illusions diminish, the harsh reality and actual perceptions rise (Murray, Holmes, \& Griffin, 1996a, 1996b). This leads to changes in perception, loss of love, and potential termination of the relationship (Murray et al., 1996a, 1996b).

My first exploratory question investigated which of the dimensions of love, behavioral violations of love, and/or changes in the perception of the beloved's character, would prove the strongest predictors of who would cease to love another and who would remain in love. My analysis revealed that the higher the rating on the following dimensions, the greater the likelihood of falling out of love with one's partner: negative change in the perception of who partner is as a person, occurrence of emotional infidelity, disagreement about the frequency of sex, and partner's sexual desire. In contrast, findings revealed that the higher the rating on the following dimensions, the greater the likelihood of remaining in love with one's partner: investment in the wellbeing of the partner, exclusiveness of the relationship maintained, financial responsibilities met, confiding in the partner, and enjoyment of the partner/relationship. An unexpected significant finding was that unacceptable sexual behavior was linked to an increased likelihood of remaining in love with one's partner. This result was unexpected because one would expect that individuals who are in relationships where their partner engages in unacceptable sexual behavior would cause them to be more likely to fall out of love with that partner. Of note here is the consistency of my results with those of Beste et al. (2003) in the critical matter of individuals experiencing dramatic negative changes in their perception of who their partner is as a person. These results suggest that the 
perception of the partner is extremely important in distinguishing between those who remain in love and those who fall out of love with their partners.

My final exploratory question concerned which of the dimensions of love, behavioral violations of love, and/or changes in the impression of the beloved's character, would be the strongest predictors of relationship satisfaction within the SIL group. I found that perception of the partner, respect for the partner, absence of secret-keeping, and meeting financial responsibilities were the most significant predictors of satisfaction among those participants who stated that they were still in love with their partners. The final model was able to account for $80 \%$ of the variability in satisfaction. The predictors included in the final model were perception of the partner (negative predictor), secretkeeping (negative predictor), failure to maintain financial responsibilities (negative predictor), emotional infidelity (negative predictor), respect of partner (positive predictor), lack of intimate communication (negative predictor), underfunctioning (negative predictor), and frequency of sex (positive predictor). This analysis found that a lot more factors seem to be working against relationship satisfaction among those in the SIL group than factors working for it. The only two factors that were found as significant positive predictors of relationship satisfaction were respect of the partner and sexual frequency. This interesting finding could be explained by individuals in relationships being overtaken by negative behaviors on the part of their partner and not being able to move past them and gain relationship satisfaction back after something detrimental occurring (e.g., an event that essentially destroys the satisfaction beyond recovery). 


\section{Interesting and Unexpected Findings}

Though mentioned previously in this section, it is perhaps worth underscoring one finding in my study that strongly replicates a similarly strong finding in the study of Beste et al. (2003). One of the strongest findings in my research concerned participants' relative levels of endorsement of the item, "In your relationship, you have come to feel that the partner you are with is not the person you thought he or she was at the beginning of the relationship, but is instead a different and lesser person." Individuals in the FOL group responded to this item in relatively high levels, while individuals in the SIL group responded to this item in relatively low levels. The development of this new, negative perception among people who break up could occur for a variety of different reasons, many of which, data suggest, might be traced to the presence of certain violation behaviors (e.g., emotional infidelity, secret-keeping, lack of intimacy). The occurrence of these behaviors, as well as the partner failing to engage in behaviors supporting the dimensions of love (e.g., intimacy, exclusivity, understanding), data suggest, might lead to a change in the perception of one's partner if these behaviors were different from how that partner was acting previously in the relationship. All of this leads to the relationship failing to meet the person's initial expectations and interpretations of the relationship and partner. That is, if for example someone was respectful and loving at the onset of the relationship, a partner would presumably perceive these as good traits and expect them to continue. Such perceptions would likely not change unless some violation of expectations and thus violations of the dimensions of love occurred.

The second exploratory question had an unexpected result when conducting analyses. One of the significant predictors of relationship satisfaction among those in the 
SIL group was the item about frequency of sex. In the analysis, the higher the rating on this item, the higher the relationship satisfaction would be. In other words, it was found to positively predict relationship satisfaction among participants in the SIL group. However, this item is in the second part of the questionnaire about the occurrence of problem behaviors. This item asks participants about disagreements on the frequency of sex. It would be expected that this item would then be negatively related to relationship satisfaction. A speculation behind this find is how the item appears on the questionnaire itself. The bolded title of the item reads 'sexual frequency', which, if read over quickly, would just appear to be inquiring about the amount of sexual behavior in the relationship and not about disagreements. It is suspected that participants did not read the full description for the item (and only read the title) and therefore misinterpreted what the item was asking.

There was another interesting finding with respect to the analysis of the second exploratory question. In running the linear stepwise regression, during models 6 and 7, the item measuring participant's respect (considering partner as someone worthy of esteem/high regard) and the item measuring the participant estimating the level of the partner's respect towards them and the relationship (partner's respect rating) were added. When the model attempted to add both of these ratings, it removed the partner's respect rating from the analysis because, at that point, the participant's respect rating was a more significant factor and trumped the rating of partner's respect. These results show that initially, partner's respect had a rather strong, direct relationship with satisfaction. However, in later models when your respect was added in the $7^{\text {th }}$ iteration of the analysis, 
the partial relationship (i.e., partial correlation - between partner's respect and satisfaction) decreased to non-significant levels when everything was assessed together.

\section{Strengths, Limitations, and Future Research Ideas}

A strength in this study included the type of sample that was recruited. The use of MTurk (instead of a college student population) allowed for a greater variety of participants of different ages and backgrounds than Beste et al.'s (2003) sample. My sample also included many married participants who had longer-term relationships than most college students. Another strength in this study included the addition of variables that were examined and the modernization of the wording in the questionnaire. This allowed the inclusion of important variables that were not examined in prior research (Beste et al., 2003). Another strength of my study included the addition of a relationship satisfaction scale. This addition allowed me to help determine which factors are especially important in predicting relationship satisfaction among those who are still in love with their current partner. Finally, my study included the use of random assignment of participants to the experimental condition. This methodological change from the Beste et al. (2003) research helped to ensure that the participants were similar on all other characteristics except for the manipulation to which they were assigned to answer about a current or past relationship.

One limitation in this study regards the nature of the sample. Although utilizing MTurk allowed for a more diverse and more nationally representative sample compared to undergraduates, the participants in this study were only recruited from one source. In future research, it would be ideal to recruit participants from multiple sources to gain the 
most nationally representative sample possible (e.g., college students, MTurk, and other websites).

A second related limitation is that the sample was predominantly Caucasian and predominantly female. Further, the size of the sample did not permit sufficient diversity and thus did not allow the results to be generalizable across different ethnicities and genders. Having this relatively small sample size significantly limits the scope of any inferences that can be made for men and individuals of various ethnic backgrounds. A way to address this problem in future research, again, would be to recruit male participants and participants of varying ethnic backgrounds to allow for more generalizability to nationwide samples.

Another limitation in the present research concerns potential biases that could impact the responses that participants provided. Participants in the FOL group are answering about a prior relationship where they were once in love with that partner but fell out of love with them over the course of the relationship, while participants in the SIL group are answering about their current relationship where they are still in love with their partner. This raises the possibility that their responses may be skewed with a hindsight bias, where they view the prior relationship failing (falling out of love with a previous partner) as more predictable now looking back on it than it actually was when it was happening. If the participants were impacted by this bias, it could impact how they answer the items on the questionnaire. The participants may also be influenced by a comparative bias (with current or past partner), where they compare their current partner with a past partner (or vice versa) and only base their answers to the items on this comparison. Another type of bias that may influence the participants is a confirmation 
bias. This bias would include the participants only searching for information that aligns and confirms their preconceptions about the relationship they answered the items about. A longitudinal study that tracked the occurrence of each of these possibilities over time, coupled with a survival analysis, might serve to correct for such potential biases. A survival analysis would focus on the time up until the participant fell out of love with that partner to give a better indication of what specifically influenced the cessation of love and when exactly it began to occur.

A related limitation includes the time frames that the participants were instructed to have guide their answers to the items on the questionnaire. The participants in the SIL group were instructed to answer about their current relationship at the particular time they completed the questionnaire while the participants in the FOL group were instructed to answer about a past relationship at the point that they began to fall out of love with that partner. This comparison of time frames could be problematic because those in the SIL group may be answering the items when their relationship is at a peak point while those in the FOL group were answering the items when their relationship was not at its peak point.

\section{Conclusions}

The importance of identifying specific factors that are linked to individuals remaining in love with a partner as well as identifying specific factors that are linked to individuals ceasing to love a partner has clear benefits to helping understand more about the nature of romantic love relationships. Some benefits from gaining more information on these specific factors that "kill" love may help individuals in romantic relationships to become more aware of specific behaviors that will help them in their relationship or hurt 
them in their relationship so they may attempt to engage in the positive and critical actions and avoid engaging in the negative behaviors. This helps individuals because the failure of love and romantic relationships leads to serious consequences for many individuals including suffering, emotional problems, family problems, financial problems, and legal problems. By helping to become more aware on how to maintain healthy and satisfying romantic relationships, people could be more proactive in their role of maintaining their emotional connection of love with their partners. Despite much research being conducted on the maintenance of romantic relationships as well as break up of relationships, there is still a gap in current literature to identify specific factors associated with maintaining loving relationships and identifying specific factors associated with the ending of loving relationships. Previous research and my study have identified a large number of seemingly important factors linked to falling out of love, perhaps most notably that of coming to regard a partner as a different and lesser person than one originally thought, the largest finding in my research and previous research of Beste et al. (2003). A further important finding in my study was related to attempting to find factors that were the strongest predictors of relationship satisfaction among participants who answered the items on the questionnaire about their current love relationship. The analysis on this research question interestingly found that there are many more factors that appear to be working against satisfaction in a romantic relationship than factors that appear to be working for it. This indicates an implication that romantic relationships take a lot of effort on both partners to maintain feelings of satisfaction in their relationship. Further research in these matters would be beneficial to individuals interested in learning more about which specific factors in their core 
relationships are especially essential to maintaining love, and which are most likely to result in the failure of such love to survive.

Overall, the primary implication of the results of my research is that "killing love" may be seen as a matter occurring when a partner fails to attend to the maintenance of specific critical dimensions of romantic love. If a person behaves, or fails to behave, in such a way as to maintain their commitment to attending to the best interests of the partner, does not honor exclusivity, does not appreciate and accept the partner, does not maintain intimacy, and more, the result may be a loss of love - a "death" of love - on the part of their partners. 


\section{REFERENCES}

Acevedo, B. P., \& Aron, A. (2009). Does a long-term relationship kill romantic love? Review of General Psychology, 13(1), 59-65. doi: 10.1037/a0014226

Amato, P. R., \& Previti, D. (2003). People's reasons for divorcing: Gender, social class, the life course, and adjustment. Journal of Family Issues, 24(5), 602-626. doi: 10.1177/0192513X03024005002

Aron, A., \& Aron, E. (1986). Love and expansion of self: Understanding attraction and satisfaction. New York, NY: Hemisphere.

Aron, A., Fisher, H. E., \& Strong, G. (2006). Romantic love. In A. Vangelisti \& D. Perlman (Eds.), The cambridge handbook of personal relationships (pp. 595-614). New York: Cambridge University Press. doi: 10.1017/CBO9780511606632.033

Azrin, N. H., Naster, B. J., \& Jones, R. (1973). Reciprocity counseling: A rapid learning based procedure for marital counseling. Behaviour Research and Therapy, 11(4), 365-382. doi: 10.1016/0005-7967(73)90095-8

Barry, W. L. (1970). Marriage research and conflict: An integrative review. Psychological Bulletin, 73(1), 41-54. doi: 10.1037/h0028474

Beitzig, L. (1989). Causes of conjugal dissolution: A cross-cultural study. Current Anthropology, 30(5), 654-676. doi: 10.1086/203798

Bergner, R. M. (2000). Love and barriers to love: An analysis for psychotherapists and others. American Journal of Psychotherapy, 54(1), 1-17.

Bergner, R. M., \& Bridges, A. J. (2002). The significance of heavy pornography involvement for romantic partners: Research and clinical implications. Journal of Sex and Marital Therapy, 28(3), 193-206. doi: 10.1080/009262302760328235

Bergner, R. M., Davis, K. E., Saturnus, L., Walley, S., \& Tyson, T. (2013). Characteristics of romantic love: An empirically based essentialist account. In R. Bergner, K. Davis, F. Lubuguin, \& W. Schwartz (Eds.), Advances in descriptive psychology, vol. 10 (pp. 219-240). Ann Arbor, MI: Descriptive Psychology Press. 
Berscheid, E. (2006). Searching for the meaning of "love". In R. J. Sternberg \& K. Weis (Eds.), The new psychology of love (pp. 171-183). New Haven, CT: Yale University Press.

Berscheid, E. (2010). Love in the fourth dimension. Annual Review of Psychology, 61, 125. doi: 10.1146/annurev.psych.093008.100318

Berscheid, E., \& Regan, P. (2005). The psychology of interpersonal relationships. New York, NY: Prentice Hall.

Berscheid, E., \& Walster [Hatfield] E. H. (1974). A little bit about love. In T. L. Hutson (Ed.), Foundations of interpersonal attraction (pp. 157-215). New York, NY: Academic.

Beste, S. A., Bergner, R. M., \& Nauta, M. M. (2003). What keeps love alive? An empirical investigation. Family Therapy, 30(3), 125-141. Billings, A. (1979). Conflict resolution in distressed and nondistressed married couples. Journal of Consulting and Clinical Psychology, 47(2), 368-376. doi: 10.1037/0022006X.47.2.368

Birchler, G. R., \& Webb, L. J. (1977). Discriminating interaction behaviors in happy and unhappy marriages. Journal of Consulting and Clinical Psychology, 45(3), 494495. doi: 10.1037/0022-006X.45.3.494

Bowlby, J. (1979). The making and breaking of affectional bonds. London: Tavistock.

Bretscher, F., \& Bergner, R. M. (1991). Relational qualities as factors in mate selection decisions. In M. Roberts \& R. Bergner (Eds.), Advances in descriptive psychology, vol. 6 (pp. 107-126). Ann Arbor, MI: Descriptive Psychology Press.

Bridges, A. J., Bergner, R. M., \& Hesson-McInnis, M. (2003). Romantic partner's use of pornography: Its significance for women. Journal of Sex and Marital Therapy, 29, 1-14. doi: 10.1080/713847097

Buelhlman, K., Gottman, J. M., \& Katz, L. (1992). How a couple views their past predicts their future: Predicting divorce from an oral history interview. Journal of Family Psychology, 5(3-4), 295-318. doi: 10.1037/0893-3200.5.3-4.295

Button, C. M., \& Collier, D. R. (June 1991). A comparison of people's concepts of love and romantic love. Paper presented at the Canadian Psychological Conference, Calgary, Alberta.

Buunk, B. (1995). Sex, self-esteem, dependency, and extradyadic sexual experience as related to jealousy responses. Journal of Social and Personal Relationships, 12(1), 147-153. doi: 10.1177/0265407595121011 
Canary, D. J., \& Stafford, L. (1992). Relational maintenance strategies and equity in marriage. Communication Monographs, 59(3), 243-267. doi:

$10.1080 / 03637759209376268$

Canary, D. J., \& Stafford, L. (1994). Maintaining relationships through strategic and routine interaction. In Canary, D. J. \& Stafford, L. (Eds.), Communication and relational maintenance (pp. 3-22). San Diego, CA: Academic Press.

Cano, A., \& O’Leary, K. D. (2000). Infidelity and separations precipitate major depressive episodes and symptoms of nonspecific depression and anxiety. Journal of Consulting and Clinical Psychology, 68(5), 774-781. doi: 10.1037/0022006X.68.5.774

Clark, M. S., \& Monin, J. K. (2006). Giving and receiving communal responsiveness as love. In R. J. Sternberg \& K. Weis (Eds.), The new psychology of love (pp. 200221). New Haven, CT: Yale University Press.

Cole, T. (2001). Lying to the one you love: The use of deception in romantic relationships. Journal of Social and Personal Relationships, 18(1), 107-129. doi: $10.1177 / 0265407501181005$

Collins, N. L. (1996). Working models of attachment: Implications for explanation, emotion, and behavior. Journal of Personality and Social Psychology, 71(4), 810832. doi: 10.1037/0022-3514.71.4.810

Collins, N. L., \& Allard, L. M. (2001). Cognitive representations of attachment: The content and function of working models. In G. J. O. Fletcher \& M. S. Clark (Eds.), Blackwell handbook of social psychology: Interpersonal processes (pp. 60-85). Oxford: Blackwell.

Cramer, D. (1998). Close relationships: The study of love and friendship. New York, NY: Oxford University Press.

Dainton, M., \& Stafford, L. (1993). Routine maintenance behaviors: A comparison of relationship type, partner similarity, and sex differences. Journal of Social and Personal Relationships, 10(2), 255-271. doi: 10.1177/026540759301000206

Davis, M. S. (1973). Intimate relations. New York, NY: Free Press.

Davis, K. (1985). Near and dear: Friendship and love compared. Psychology Today, (February), pp. 22-30.

Davis, K., \& Todd, M. (1982). Friendship and love relationships. In K. Davis \& T. Mitchell (Eds.), Advances in descriptive psychology, vol. 2 (pp. 79-122). Greenwich, CT: JAI Press. 
Dindia, K. (2000). Relationship maintenance. In C. Hendrick \& S. S. Hendrick (Eds.), Close relationships: A sourcebook (pp. 286-299). Thousand Oaks, CA: Sage. doi: 10.4135/9781452220437.n21

Dion, K. L., \& Dion, K. K. (1993). Gender and ethnocultural comparisons in styles of love. Psychology of Women Quarterly, 17(4), 463-473. doi: 10.1111/j.14716402.1993.tb00656.x

Falconier, M. K., \& Epstein, N. B. (2010). Relationship satisfaction in argentinean couples under economic strain: Gender differences in a dyadic stress model. Journal of Social and Personal Relationships, 27(6), 781-799. doi: $10.1177 / 0265407510373260$

Fals-Stewart, W., Birchler, G. R., \& O'Farrell, T. J. (1999). Drug-abusing patients and their intimate partners: Dyadic adjustment, relationship stability, and substance abuse. Journal of Abnormal Psychology, 108(1), 11-23. doi: 10.1037/0021843X.108.1.11

Fehr, B. (1988). Prototype analysis of the concepts of love and commitment. Journal of Personality and Social Psychology, 55(4), 557-579. doi: 10.1037/00223514.55.4.557

Fehr, B. (1993). How do I love thee...? Let me consult my prototype. In S. Duck (Ed.), Understanding personal relationships, vol. 1, Individuals in relationships (pp. 87120). Newbury Park, CA: Sage.

Fehr, B. (1994). Prototype-based assessments of laypeople's views of love. Personal Relationships, 1, 309-331. doi: 10.1111/j.1475-6811.1994.tb00068.x

Fehr, B. (2006). The prototype approach to studying love. In R. J. Sternberg \& K. Weis (Eds.), The new psychology of love (pp. 225-246). New Haven, CT: Yale University Press.

Fehr, B., \& Broughton, R. (2001). Gender and personality differences in conceptions of love: An interpersonal theory analysis. Personal Relationships, 8(2), 115-136. doi: 10.1111/j.1475-6811.2001.tb00031.x

Fehr, B., \& Broughton, R. (2004). Individual and dyadic conceptions of love: Implications for thoughts, feelings, and behavior in close relationships. Unpublished manuscript.

Fehr, B., \& Russell, J. A. (1991). The concept of love viewed from a prototype perspective. Journal of Personality and Social Psychology, 60(3), 425-438. doi: 10.1037/0022-3514.60.3.425 
Glass, S. P. (2002). Couple therapy after the trauma of infidelity. In A. S. Gurman \& N. S. Jacobson (Eds.), Clinical handbook of couple therapy, $3^{\text {rd }}$ ed. (pp. 488-507). New York, NY: Guilford.

Gottman, J. M. (1995). Why marriages succeed or fail: And how you can make yours last. New York, NY: Simon \& Schuster.

Gottman, J. M., \& Krokoff, L. J. (1989). Marital interaction and satisfaction: A longitudinal view. Journal of Consulting and Clinical Psychology, 57(1), 47-52. doi: 10.1037/0022-006X.57.1.47

Gottman, J. M., \& Levenson, R. W. (1992). Marital processes predictive of later dissolution: Behavior, physiology, and health. Journal of Personality and Social Psychology, 63(2), 221-233. doi: 10.1037/0022-3514.63.2.221

Gottman, J. M., \& Silver, N. (2012). What makes love last? How to build trust and avoid betrayal. New York, NY: Simon \& Schuster.

Greeley, A. (1994). Marital infidelity. Society, 31(4), 9-13. doi: 10.1007/BF02693241

Hall, J. H., \& Fincham, F. D. (2006). Relationship dissolution following infidelity: The roles of attributions and forgiveness. Journal of Social and Clinical Psychology, 25(5), 508-522. doi: 10.1521/jscp.2006.25.5.508

Harlow, H. F. (1958). The nature of love. In J. Notterman (Ed.), The evolution of psychology: Fifty years of the american psychologist (pp. 41-64). Washington, DC: American Psychological Association.

Hatfield, E. (1988). Passionate and companionate love. In R. J. Sternberg \& K. Weis (Eds.), The new psychology of love (pp. 191-217). New Haven, CT: Yale University Press.

Heavey, C. L., Layne, C., \& Christensen, A. (1993). Gender and conflict structure in marital interaction: A replication and extension. Journal of Consulting and Clinical Psychology, 61(1), 16-27. doi: 10.1037/0022-006X.61.1.16

Hegi, K. E., \& Bergner, R. M. (2010). What is love? An empirically based account. Journal of Social and Personal Relationships, 27(5), 620-636. doi: 10.1177/0265407510369605

Hendrick, C., \& Hendrick, S. S. (1986). A theory and method of love. Journal of Personality and Social Psychology, 50(2), 392-402. doi: 10.1037/00223514.50.2.392 
Hendrick, S. S. (1988). A generic measure of relationship satisfaction. Journal of Marriage and Family, 50(1), 93-98. doi: 10.2307/352430

Holmes, J. G. (2002). Interpersonal expectations as the building blocks of social cognition: An interdependence theory perspective. Personal Relationships, 9(1), 1-26. doi: 10.1111/1475-6811.00001

Holmes, J. G., \& Rempel, J. K. (1989). Trust in close relationships. In C. Hendrick (Ed.), Close relationships: A sourcebook (pp. 187-220). Thousand Oaks, CA: Sage.

Johnson, D. W., \& Johnson, R. T. (2005). New developments in social interdependence theory. Genetic, social, and general psychology monographs,131(4), 285-358. doi: 10.3200/MONO.131.4.285-358

Katz, J., Kuffel, S. W., \& Brown, F. A. (2006). Leaving a sexually coercive dating partner: A prospective application of the investment model. Psychology of Women Quarterly, 30(3), 267-275. doi: 10.1111/j.1471-6402.2006.00295.x

Katz, J., \& Myhr, L. (2008). Perceived conflict patterns and relationship quality associated with verbal sexual coercion by male dating partners. Journal of Interpersonal Violence, 23(6), 798-814. doi: 10.1177/0886260507313949

Kelly, H. H. (1983/2002). Love and commitment. In H. H. Kelley, E. Berscheid, A. Christensen, J. H. Harvey, T. L. Huston, G. Levinger, E. McClintock, L. A. Peplau, \& D. R. Peterson (Eds.), Close relationships (pp. 265-314). Clinton Corners, NY: Percheron.

Kim, H. K., Laurent, H. K., Capaldi, D. M., \& Feingold, A. (2008). Men's aggression towards women: A 10-year panel study. Journal of Marriage and Family, 70(5), 1169-1187. doi: 10.1111/j.1741-3737.2008.00558.x

Knapp, M. L. (1984). Interpersonal communication and human relationships. Boston, MA: Allyn \& Bacon.

Kurdek, L. A. (1995). Predicting change in marital satisfaction from husbands' and wives' conflict resolution styles. Journal of Marriage and Family, 57(1),153-164. doi: $10.2307 / 353824$

Lawrence, E., \& Bradury, T. N. (2001). Physical aggression as a predictor of marital dysfunction: A longitudinal analysis. Journal of Family Psychology, 15(1), 135154. doi: 10.1037/0893-3200.15.1.135

Lawrence, E., \& Bradbury, T. N. (2007). Trajectories of change in physical aggression and marital satisfaction. Journal of Family Psychology, 21(2), 236-247. doi: 10.1037/0893-3200.21.2.236 
Lederer, W. J., \& Jackson, D. D. (1968). The mirage of marriage. New York, NY: Norton.

Levinger, G. (1965). Martial cohesiveness and dissolution: An integrative review. Journal of Marriage and the Family, 27(1), 19-28. doi: 10.2307/349801

Luby, V., \& Aron, A. (July 1990). A prototype structuring of love, like, and being-inlove. Paper presented at the Fifth International Conference on Personal Relationships, Oxford.

McCornack, S. A., \& Levine, T. R. (1990). When lies are uncovered: Emotional and relational outcomes of discovered deception. Communication Monographs, 57(2), 119-138. doi: 10.1080/03637759009376190

Mikulincer, M., Shaver, P. R., Gillath, O., \& Nitzberg, R. A. (2005). Attachment, caregiving, and altruism: Boosting attachment security increases compassion and helping. Journal of Personality and Social Psychology, 89(5), 817-839. doi: 10.1037/0022-3514.89.5.817

Miller, G. R., Mongeau, P. A., \& Sleight, C. (1986). Fudging with friends and lying to lovers: Deceptive communication in personal relationships. Journal of Social and Personal Relationships, 3(4), 495-512. doi: 10.1177/0265407586034006

Mudar, P., Leonard, K. E., \& Soltysinski, K. (2001). Discrepant substance use and marital functioning in newlywed couples. Journal of Consulting and Clinical Psychology, 69(1), 130-134. doi: 10.1037/0022-006X.69.1.130

Murray, S. L., Holmes, J. G., \& Griffin, D. W. (1996a). The benefits of positive illusions: Idealization and the construction of satisfaction in close relationships. Journal of Personality and Social Psychology, 70(1), 79. doi: 10.1037/0022-3514.70.1.79

Murray, S. L., Holmes, J. G., \& Griffin, D. W. (1996b). The self-fulfilling nature of positive illusions in romantic relationships: love is not blind, but prescient. Journal of Personality and Social Psychology, 71(6), 1155. doi: 10.1037/00223514.71.6.1155

O'Leary, K., Acevedo, B. P., Aron, A., Huddy, L., \& Mashek, D. (2012). Is long-term love more than a rare phenomenon? If so, what are its correlates? Social Psychological and Personality Science, 3(2), 241-249. doi: $10.1177 / 1948550611417015$

O'Leary, K. D., Barling, J., Arias, I., Rosenbaum, A., Malone, J., \& Tyree, A. (1989). Prevalence and stability of physical aggression between spouses: A longitudinal analysis. Journal of Consulting and Clinical Psychology, 57(2), 263-268. doi: 10.1037/0022-006X.57.2.263 
Ossorio, P. G. (1997). Essays on clinical topics: The collected works of Peter G. Ossorio, vol. 2. Ann Arbor, MI: Descriptive Psychology Press.

Panuzio, J., \& DiLillo, D. (2010). Physical, psychological, and sexual intimate partner aggression among newlywed couples: Longitudinal prediction of marital satisfaction. Journal of Family Violence, 25(7), 689-699. doi: 10.1007/s10896010-9328-2

Pasch, L. A., \& Bradbury, T. N. (1998). Social support, conflict, and the development of marital dysfunction. Journal of Consulting and Clinical Psychology, 66(2), 219230. doi: 10.1037/0022-006X.66.2.219

Patterson, G. R., Weiss, R. L., \& Hops, H. (1976). Training of marital skills: Some problems and concepts. In H. Leitenberg (Ed.), Handbook of behavior modification (pp. 242-254). New York, NY: Appleton-Century-Crofts.

Planalp, S., \& Honeycutt, J. M. (1985). Events that increase uncertainty in personal relationships. Human Connection Research, 11(4), 593-604.

Raush, H. L., Barry, W. A., Hertel, R. K., \& Swain, M. A. (1974). Communication, conflict, and marriage. San Francisco, CA: Jossey-Bass.

Reis, H. T., \& Patrick, B. C. (1996). Attachment and intimacy: Component processes. In E. T. Higgens \& A. W. Kruglanski (Eds.), Social psychology: Handbook of basic principles (pp. 523-563). New York, NY: Guilford Press.

Regan, P. C. (1998). Of lust and love: Beliefs about the role of sexual desire in romantic relationships. Personal Relationships, 5(2), 139-157. doi: 10.1111/j.14756811.1998.tb00164.x

Reis, H. T., \& Shaver, P. (1988). Intimacy as an interpersonal process. In S. Duck (Ed.), Handbook of personal relationships: Theory, relationships, and interventions (pp. 367-389). Chichester, U.K.: Wiley.

Roberts, M. (1982). Men and women: Partners, lovers, and friends. In K. Davis \& T. Mitchell (Eds.), Advances in descriptive psychology, vol. 2 (pp. 57-78). Greenwich, CT: JAI Press.

Roberts, M. (1985). I and thou: A study in personal relationships. In K. Davis \& T. Mitchell (Eds.), Advances in descriptive psychology, vol. 4 (pp. 231-258). Greenwich, CT: JAI Press.

Roberts, L. J. (2000). Fire and ice in marital communication: Hostile and distancing behaviors as predictors of marital distress. Journal of Marriage and Family, 62(3), 693-707. doi: 10.1111/j.1741-3737.2000.00693.x 
Rosch, E. H. (1973a). Natural categories. Cognitive Psychology, 4(3), 328-350. doi: 10.1016/0010-0285(73)90017-0

Rosch, E. H. (1973b). On the internal structure of perceptual and semantic categories. In T. E. Moore (Ed.), Cognitive development and the acquisition of language (pp. 111-144). New York: Academic Press.

Rusbult, C. E. (1980). Commitment and satisfaction in romantic associations: A test of the investment model. Journal of experimental social psychology,16(2), 172-186. doi: 10.1016/0022-1031(80)90007-4

Rusbult, C. E. (1983). A longitudinal test of the investment model: The development (and deterioration) of satisfaction and commitment in heterosexual involvements. Journal of Personality and Social Psychology, 45(1), 101. doi: 10.1037/0022-3514.45.1.101

Scanzoni, J. A. (1965). A reinquiry into marital disorganization. Journal of Marriage and Family, 27(4), 483-491. doi: 10.2307/350188

Schneider, J. P. (2000). Effects of cybersex addiction on the family: Results of a survey. Sexual Addiction \& Compulsivity, 7(1-2), 31-58. doi: 10.1080/10720160008400206

Schneider, J. P., Corley, M. D., \& Irons, R. R. (1998). Surviving disclosure of infidelity: Results of an international survey of 164 recovering sex addicts and partners. Sexual Addiction \& Compulsivity, 5(3), 189-217. doi: 10.1080/10720169808400162

Schneider, J. P., \& Schneider, B. H. (1990). Sex, lies, and forgiveness: Couples speaking on healing from sex addiction. Center City, MN: Hazelden Educational Materials.

Shackelford, J. K., LeBlanc, G. J., \& Drass, E. (2000). Emotional reactions to infidelity. Cognition \& Emotion, 14(5), 643-659. doi: 10.1080/02699930050117657

Singer, I. (1984). The nature of love: From plato to luther (vol. 1, $2^{\text {nd }}$ ed.). Chicago, IL: The University of Chicago Press.

Sprecher, S., \& Fehr, B. (2005). Compassionate love for close others and humanity. Journal of Social and Personal Relationships, 22(5), 629-651. doi: $10.1177 / 0265407505056439$

Sprecher, S., \& Metts, S. (1989). Development of the "romantic beliefs scale" and examination of the effects of gender and gender-role orientation. Journal of Social and Personal Relationships, 6(4), 387-411. doi: 10.1177/0265407589064001 
Stafford, L., \& Canary, D. J. (1991). Maintenance strategies and romantic relationship type, gender, and relational characteristics. Journal of Social and Personal Relationships, 8(2), 217-242. doi: 10.1177/0265407591082004

Stuart, R. B. (1969). Operant interpersonal treatment for marital discord. Journal of Consulting and Clinical Psychology, 33(6), 675-682. doi: 10.1037/h0028475

Wiederman, M. W. (1997). Extramarital sex: Prevalence and correlates in a national survey. The Journal of Sex Research, 34(2), 167-174. doi: $10.1080 / 00224499709551881$

Wiederman, M. W., \& Hurd, C. (1999). Extradyadic involvement during dating. Journal of Social and Personal Relationships, 16(2), 265-274. doi: 10.1177/0265407599162008

Wieselquist, J., Rusbult, C. E., Agnew, C. R., \& Foster, C. A. (1999). Commitment, prorelationship behavior, and trust in close relationships. Journal of Personality and Social Psychology, 77(5), 942-966. doi: 10.1037/0022-3514.77.5.942

Wilsnack, S. C., \& Wilsnack, R. W. (1990, June). Marital drinking and the quality of marital relationships: Patterns from a U.S. longitudinal survey. Paper presented at the International Institute on the Prevention and Treatment of Alcoholism, Berlin, Germany. 


\title{
APPENDIX
}

\section{SURVEY QUESTIONNAIRE}

\author{
RESEARCH PARTICIPANT CONSENT FORM \\ Factors Influencing Love in Romantic Relationships \\ Dr. Raymond Bergner, Dr. Susan Sprecher, Michelle Duda \\ Illinois State University \\ Departments of Psychology and Sociology
}

\section{Purpose of Research:}

In this research, the investigators are interested in assessing factors associated with maintaining or ceasing to maintain a feeling of being in love with a romantic partner.

\section{Specific Procedures to be Used:}

You will be asked to complete a questionnaire from your computer. The questionnaire will include a variety of questions about different relationship characteristics (e.g., trust and respect), the occurrence of problem behaviors in the relationship, and satisfaction derived from the relationship.

\section{Duration of Participation:}

Your participation should take no more than 30 minutes. In pre-study trials, participants typically took around 15 minutes.

\section{Requirements:}

You must be at least 20 years of age and a resident of the USA.

To participate in this study you also need to meet BOTH of the following requirements:

1) You must currently in a romantic love relationship of at least 6 months duration and currently have a feeling of being "in love" with your partner.

\section{AND}

2) You must have been involved in a previous romantic love relationship of at least 6 months duration in which you would describe yourself as having been at one time "in love" with that partner but lost this feeling over the course of the relationship; that is, you ceased to be in love or "fell out of love" with this person.

If you do not meet the requirements listed above, we ask that you please do not complete this survey. 


\section{Benefits to the Individual:}

You may be able to gain insight on your current or past intimate love relationships by participating in this research. Further, you may be able to learn more about what relationship characteristics, positive behaviors, and negative behaviors may be especially important to you as an individual in your intimate personal relationships. You may also contact this researcher in the future to learn about the results of this research.

\section{Compensation:}

You will receive $\$ .40$ compensation via Amazon.com's MTurk and PayPal for participating. You can skip any question(s) for any reason without penalty.

\section{Risks to the Individual:}

When filling out this questionnaire, it is possible that you might find an occasional item uncomfortable, upsetting, or otherwise objectionable. Please feel free to skip any such items and/or discontinue your participation at any time.

\section{Confidentiality:}

All data obtained in this research will be kept on a secure server and computers. You do not indicate your name anywhere on the survey itself, so your participation is completely anonymous. We do ask for some demographic information to help us understand the nature of the sample and examine trends in the data for people of different experiences. It is virtually impossible that these demographic items would enable someone to identify any participant, but nonetheless we will take steps to protect the confidentiality of all participants' responses in order to minimize this risk. All data will be kept on a secure server that is password-protected.

\section{Voluntary Nature of Participation:}

Participation in this research project is entirely voluntary. If you agree to participate, you may withdraw your participation at any time without penalty. Further, as already stated, you should feel free to not answer any question for any reason.

\section{Human Subject Statement:}

If you have any questions about this research project, you can contact Dr. Bergner (rmbergn@ilstu.edu) or Michelle Duda (mlduda@ilstu.edu ). Any questions regarding your rights as a research participant or research-related injuries may be directed to the Research, Ethics, and Compliance Office at Illinois State University, (309) 438-2529. Their email address is rec@ilstu.edu

\section{Web-based Implied Consent Script}

Thank you for considering participating in this study.

Please read the information below and, if you agree to the conditions, click the link to begin the survey. Please note that you must be at least 18 years of age to give consent to participate in this research. 


\section{Purpose of the Study:}

To assess various factors that influence intimate love relationships.

\section{Description of the Study:}

This web-based survey should take approximately 15-30 minutes to complete. You will be asked to respond to questions about a current intimate love relationship that you are in or about a previous intimate love relationship that you have been in in the past. You will be asked about specific factors in that relationship and questions about relationship satisfaction.

\section{Possible Risks:}

When filling out this questionnaire, it is possible that you might find an item unpleasant, upsetting, or otherwise objectionable. However, you are free to skip any items and/or discontinue your participation at any time.

\section{Possible Benefits:}

You may be able to gain insight on your current or past intimate love relationships by answering the items. You may be able to learn more about the factors included in this research and how important these factors are to you and your personal relationships. You also have the opportunity to contact this researcher in the future to learn about the results of this research.

\section{Compensation for your Time:}

You will receive $\$ .40$ compensation via Amazon.com's MTurk and PayPal for participating.

\section{Confidentiality:}

All data will be kept on a secure server and computers. You do not need to indicate your name anywhere on the survey itself. We do ask for some demographic information, which will help us understand the nature of the sample and examine trends in the data for people of different experiences. It is unlikely that these demographic items would enable someone to narrow down the identity of any participants, but we will take steps to protect the confidentiality of all students' responses in order to minimize this risk. All data will be kept on a secure server that is password-protected.

\section{Opportunities to Question:}

Any technical questions about this research may be directed to: Michelle Duda (mlduda@ilstu.edu), or her thesis advisor, Dr. Raymond Bergner (rmbergn @ilstu.edu).

Any questions regarding your rights as a research participant or research-related injuries may be directed to ISU's Research, Ethics, and Compliance Office, 438-2529.

\section{Opportunities to Withdraw at Will:}

If you decide now or at any point to stop participating, you are free to do so at no penalty to you. You are free to skip specific questions. You will receive compensation regardless 
of the number of questionnaire items you complete. You would simply advance to the end of the survey if you choose not to complete questions.

\section{Opportunities to be Informed of Results:}

The results of this study will be available by August, 2014. If you wish to be informed of the results, please contact Michelle Duda at mlduda@ilstu.edu, and she will send you a summary report when it is available. In addition, the results from this study may be published in a psychology journal. In such an article, participants would be identified only as undergraduate students at a large Midwestern university.

If you understand the above information and agree to participate in this study, please click the link to begin the survey.

\section{Survey Items and Instructions}

\section{$\underline{\text { Demographic Questions }}$}

Gender (choose one):

1. Male

2. Female

3. Other, please specify

Race/ethnicity (choose one):

1. Caucasian

2. African-American/Black

3. Asian-American

4. Hispanic/Latino-American

5. Native American

6. Bi racial

7. Multi racial

8. Other, please specify

What is your age?

Does your birth date fall on an even or an odd numbered day of the month? For example, June $17^{\text {th }}$ would fall on an odd number or July $2^{\text {nd }}$ would fall on an even number. This is being asked only to randomly assign you to respond to the questionnaire items based on a current or past romantic relationship.

1. My birthday falls on an even-numbered day of the month.

2. My birthday falls on an odd-numbered day of the month.

\section{Intimate Relationships Questionnaire}




\section{Version 1: Still in Love Participants}

[Note: If the participants are randomly assigned to respond to the items based on the relationship that they are currently in, they will be given this version of the survey.]

Instructions: To begin, please think of YOUR CURRENT LOVE RELATIONSHIP, which should be one in which you currently have a feeling of being in love with your partner. Then, keeping this relationship in mind, please respond to the questions regarding how well each description fits or does not fit your relationship with your partner.

\section{$\underline{\text { Relationship Dimensions }}$}

\section{Care for the Partner's Well-being:}

In some relationships, we have a sense that each of us truly cares about the well-being of the other. We have a sense that each of us genuinely cares about, and is willing to make personal efforts when needed, to further the other's welfare and happiness. Such caring may be expressed in many different ways. For example, it might be expressed in a desire to give to the other in ways that will make him or her happy...or in wanting to help and to stand by each other when the other is hurt or ill or unhappy...or in being willing to do things to assist each other in important matters. In all of this, finally, our sense is that each of us is not just giving to get -- are not just doing all of this because there is something in it for us. Rather, each of us is doing it because the welfare and happiness of our partner genuinely matters to us.

To what degree does this description fit...

$\begin{array}{cclrrrl}1 & 2 & 3 & 4 & 5 & 6 & 7 \\ \text { Does Not Fit } & & \text { Somewhat Fits } & & & \text { Fits Very Well }\end{array}$

1. Your feelings or beliefs towards your partner and the relationship

2. Your partner's feelings or beliefs towards you and the relationship

\section{Exclusiveness:}

In some relationships, we are exclusive. That is, we regard each other, romantically speaking, as our "one and only." We have a sense that we want to have this kind of a relationship only with this partner. We wish to form a sort of "two person community" 
in which no one else is allowed in romantically_no one else is allowed to relate to us in just the way that this person does. While we may continue friendships and other relationships just as before, there is a specialness to the relationship with our romantic partner which is unique to it and reserved for it only.

To what degree does this description fit...

\begin{tabular}{cllllll}
1 & 2 & 3 & 4 & 5 & 6 & 7 \\
Does Not Fit & \multicolumn{3}{l}{ Somewhat Fits } & & & Fits Very Well
\end{tabular}

1. Your feelings or beliefs towards your partner and the relationship

2. Your partner's feelings or beliefs towards you and the relationship

\section{Acceptance:}

In some relationships, we have the sense that we are accepted by the other as the person we are. Even though our partner may at times object to certain actions of ours (e.g., to our being late or being messy or driving too fast), we do not get the sense that they want us to be different persons. They do not seem, for example, to want to make us over to be different persons, or to be disappointed that we are not more like some other person they admire. Rather, our sense in the relationship is that we are basically accepted as the person we are.

To what degree does this description fit...

\begin{tabular}{cllllll}
1 & 2 & 3 & 4 & 5 & 6 & 7 \\
Does Not Fit & \multicolumn{3}{l}{ Somewhat Fits } & & & Fits Very Well
\end{tabular}

1. Your feelings or beliefs towards your partner and the relationship

2. Your partner's feelings or beliefs towards you and the relationship Attention Check:

As an attention check, please select "Does not fit" (or one) for this item. We use this item to identify possible workers who may be randomly responding to questions. Thank you for your participation and attention so far. 
As an attention check, please select "Does not fit" (or one) for this item.

$\begin{array}{lllllll}1 & 2 & 3 & 4 & 5 & 6 & 7\end{array}$

Does Not Fit Somewhat Fits Fits Very Well

\section{Sexual Desire:}

In some relationships, we have strong feelings of sexual desire for each other. We want to be physically intimate with each other -- to touch and be touched, to hold each other in our arms, and to engage in sexual intercouse and/or other sexual acts with each other.

To what degree does this description fit...

\begin{tabular}{cllllll}
1 & 2 & 3 & 4 & 5 & 6 & 7 \\
Does Not Fit & \multicolumn{3}{l}{ Somewhat Fits } & & & Fits Very Well
\end{tabular}

1. Your feelings or beliefs towards your partner and the relationship

2. Your partner's feelings or beliefs towards you and the relationship

\section{Intimate Confiding in the Other:}

In some relationships, we confide intimately to each other -- we include each other in our intimate worlds. We share with each other what is going on in our lives. We disclose intimate personal experiences and feelings, both positive and negative, to each other. We feel we can really talk to and open up with each other about deeply personal matters.

To what degree does this description fit...

\begin{tabular}{cllllll}
1 & 2 & 3 & 4 & 5 & 6 & 7 \\
Does Not Fit & \multicolumn{3}{l}{ Somewhat Fits } & & & Fits Very Well
\end{tabular}

1. Your feelings or beliefs towards your partner and the relationship

2. Your partner's feelings or beliefs towards you and the relationship

\section{Freedom to be Ourselves:}

In some relationships, we feel free to be ourselves with the other. We do not feel like we have to play any kind of false role with them, or hold back from being the way we really are. We feel like we can just relax and be the person who we really are when we are with 
them.

To what degree does this description fit...

\begin{tabular}{cllllll}
1 & 2 & 3 & 4 & 5 & 6 & 7 \\
Does Not Fit & \multicolumn{3}{l}{ Somewhat Fits } & & & Fits Very Well
\end{tabular}

1. Your feelings or beliefs towards your partner and the relationship

2. Your partner's feelings or beliefs towards you and the relationship

\section{Trust:}

In some relationships, we have a basic sense that we can trust each other-that we can count on each other not to to betray us or to violate the relationship that we have. We do not have doubts about very critical matters in our relationship (for example, our partners being sexually unfaithful, lying about significant matters, failing to keep promises, betraying confidences, or hiding important things from us).

To what degree does this description fit...

\begin{tabular}{cllllll}
1 & 2 & 3 & 4 & 5 & 6 & 7 \\
Does Not Fit & \multicolumn{3}{l}{ Somewhat Fits } & & & Fits Very Well
\end{tabular}

1. Your feelings or beliefs towards your partner and the relationship

2. Your partner's feelings or beliefs towards you and the relationship

\section{Respect:}

In some relationships, we have the sense that each of us respects the other. In other words, we consider each other to be persons who are worthy of esteem and high regard. This respect might be based on a variety of factors. We might, for example, respect each other as caring persons, as morally good persons, as intelligent persons, as capable persons, or for some combination of these and/or other qualities. Whatever the particular reasons might be, however, we find that each of us has a basic respect for the other.

To what degree does this description fit... 


\begin{tabular}{cllllll}
1 & 2 & 3 & 4 & 5 & 6 & 7 \\
Does Not Fit & \multicolumn{3}{l}{ Somewhat Fits } & & & Fits Very Well
\end{tabular}

1. Your feelings or beliefs towards your partner and the relationship

2. Your partner's feelings or beliefs towards you and the relationship

\section{Enjoyment:}

In some relationships, partners enjoy each other. They enjoy being together--enjoy being in each other's company. Even though there may be times of conflict, boredom, or tension in the relationship, for the most part, the experience of being with each other is an enjoyable one.

To what degree does this description fit...

$\begin{array}{cclrrrl}1 & 2 & 3 & 4 & 5 & 6 & 7 \\ \text { Does Not Fit } & & \text { Somewhat Fits } & & & \text { Fits Very Well }\end{array}$

1. Your feelings or beliefs towards your partner and the relationship

2. Your partner's feelings or beliefs towards you and the relationship

\section{Knowledge and Understanding:}

In some relationships, we really know and understand each other to a high degree.

Each of us knows things about the other such as his or her deepest values, most cherished goals in life, strengths, weaknesses, vulnerabilities, and interests. As a rule, this knowledge means that we will understand the reasoning and the feelings that are behind each other's actions and reactions, and will not be puzzled or confused by them. For example, if the other is troubled or moody, we are likely to be able to make a good guess as to what is bothering them. We know what "makes each other tick."

To what degree does this description fit...

$\begin{array}{cclrrrl}1 & 2 & 3 & 4 & 5 & 6 & 7 \\ \text { Does Not Fit } & & \text { Somewhat Fits } & & & \text { Fits Very Well }\end{array}$


1. Your feelings or beliefs towards your partner and the relationship

2. Your partner's feelings or beliefs towards you and the relationship

\section{Occurrence of Problem Behaviors}

Instructions: In this section of the questionnaire, we would like to inquire about the presence or absence of specific kinds of problem behaviors ON THE PART OF YOUR PARTNER.

1. Negative labeling: partner criticizes you by using highly negative labels (e.g., "loser," "narcissist," "crazy," "whore," or other very degrading labels).

$$
\begin{array}{lllllll}
1 & 2 & 3 & 4 & 5 & 6 & 7
\end{array}
$$

Never Happens Sometimes Happens Happens Reatedly

2. Defensiveness: in disagreement situations, partner primarily defends himself or herself and does not listen to and truly consider input from you.

$\begin{array}{cllllll}1 & 2 & 3 & 4 & 5 & 6 & 7 \\ \text { Never Happens } & \text { Sometimes Happens } & & \text { Happens Repeatedly }\end{array}$

3. Contempt: partner shows contempt for you by such behaviors as ridicule, sarcasm, mocking, laughing at you, putting you down, or in other ways.

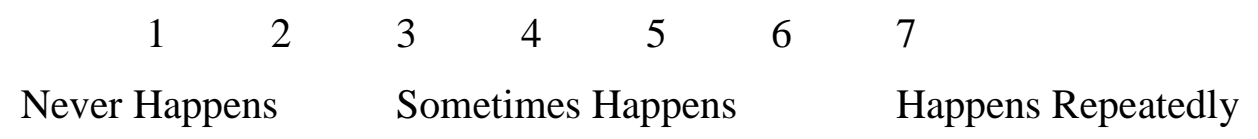

4. Stonewalling: in disagreement situations, partner totally shuts you out and refuses to listen when you are trying to make your points and express your position (e.g. refuses to listen to anything you are saying and/or leaves the situation).

$\begin{array}{cllllll}1 & 2 & 3 & 4 & 5 & 6 & 7 \\ \text { Never Happens } & \text { Sometimes Happens } & & \text { Happens Repeatedly }\end{array}$

5. Failure to address issues: partner, though you are pretty sure he or she has some issue with you, keeps it to himself or herself and will not talk about it.

$\begin{array}{lllllll}1 & 2 & 3 & 4 & 5 & 6 & 7\end{array}$

Never Happens Sometimes Happens Happens Repeatedly 
6. False agreement: partner pretends to agree with you when you believe s/he doesn't really agree (for example, in decision situations, takes the position that whatever you want is fine with him/her; or, when you think s/he is actually mad at you about something, doesn't admit it and says that everything is fine).

$\begin{array}{lllllll}1 & 2 & 3 & 4 & 5 & 6 & 7\end{array}$

Never Happens Sometimes Happens Happens Repeatedly

7. Attention Check: As an attention check, please select "Happens repeatedly" (or seven) for this item. We use this item to identify possible workers who may be randomly responding to questions. Thank you for your continued participation and attention.

$\begin{array}{cclllll}1 & 2 & 3 & 4 & 5 & 6 & 7 \\ \text { Never Happens } & & \text { Sometimes Happens } & & & \text { Happens Repeatedly }\end{array}$

8. Not sticking to the issue: in disagreement situations, partner does not focus on the issue under discussion, but brings up other things (e.g., negative events from the past, other issues, or comments about your character) that distract from the present issue.

$\begin{array}{cclccll}1 & 2 & 3 & 4 & 5 & 6 & 7 \\ \text { Never Happens } & & \text { Sometimes Happens } & & & \text { Happens Repeatedly }\end{array}$

9. Playing for a win: in disagreement situations, partner's primary goal seems to be to win the argument, not to genuinely consider the merits of what each of you has to say and, based on this, to come to a mutually acceptable solution.

$\begin{array}{ccccccc}1 & 2 & 3 & 4 & 5 & 6 & 7 \\ \text { Never Happens } & & \text { Sometimes Happens } & & & \text { Happens Repeatedly }\end{array}$

10. Physical abuse: partner hits, slaps, pushes, or is otherwise physically abusive to you.

$\begin{array}{crrrrrl}1 & 2 & 3 & 4 & 5 & 6 & 7 \\ \text { Never Happens } & & \text { Sometimes Happens } & & & \text { Happens Repeatedly }\end{array}$

11. Sexual abuse: partner forces sex upon you, or is otherwise sexually abusive.

$\begin{array}{crrrrrr}1 & 2 & 3 & 4 & 5 & 6 & 7 \\ \text { Never Happens } & & \text { Sometimes Happens } & & & \text { Happens Repeatedly }\end{array}$


12. Secret-keeping: partner withholds important information from you about matters that affect your relationship.

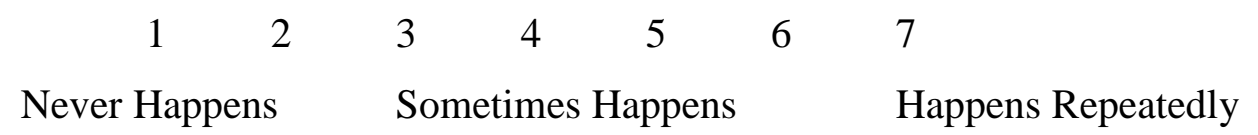

13. Lying: partner lies to you.

$\begin{array}{cllllll}1 & 2 & 3 & 4 & 5 & 6 & 7 \\ \text { Never Happens } & \text { Sometimes Happens } & & \text { Happens Repeatedly }\end{array}$

14. Taken advantage of: partner uses or exploits you for money, sex, or other purposes.
$\begin{array}{lllllll}1 & 2 & 3 & 4 & 5 & 6 & 7\end{array}$
Never Happens Sometimes Happens Happens Repeatedly

15. Lack of intimate communication: partner does not open up to you; does not share personal feelings, concerns, or other matters with you.

$\begin{array}{cllllll}1 & 2 & 3 & 4 & 5 & 6 & 7 \\ \text { Never Happens } & & \text { Sometimes Happens } & & \text { Happens Repeatedly }\end{array}$

16. Pornography use: partner views pornography to a degree that you find excessive and harmful to your relationship.

$\begin{array}{cllllll}1 & 2 & 3 & 4 & 5 & 6 & 7 \\ \text { Never Happens } & & \text { Sometimes Happens } & & \text { Happens Repeatedly }\end{array}$

17. Drug use: partner uses alcohol or other drugs to a degree that was excessive.

$\begin{array}{cllllll}1 & 2 & 3 & 4 & 5 & 6 & 7 \\ \text { Never Happens } & \text { Sometimes Happens } & & \text { Happens Repeatedly }\end{array}$

18. Underfunctioning: partner fails to hold up his or her end of responsibilities in the relationship (e.g., household chores, home maintenance, other).

$\begin{array}{cllllll}1 & 2 & 3 & 4 & 5 & 6 & 7 \\ \text { Never Happens } & & \text { Sometimes Happens } & & \text { Happens Repeatedly }\end{array}$

19. Financial responsibilities: partner fails to hold up his or her end of financial responsibilities in the relationship.

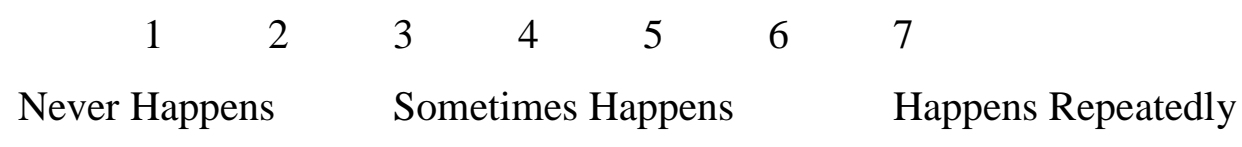


20. Sexual frequency: disagreements between you and your partner about the frequency with which you and your partner desire sex.

$\begin{array}{cclccll}1 & 2 & 3 & 4 & 5 & 6 & 7 \\ \text { Never Happens } & & \text { Sometimes Happens } & & \text { Happens Repeatedly }\end{array}$

21. Emotional infidelity: partner forms emotional attachments with members of the opposite sex that you feel are overly close and intimate.

$\begin{array}{lllllll}1 & 2 & 3 & 4 & 5 & 6 & 7\end{array}$

Never Happens Sometimes Happens Happens Repeatedly

22. Sexual infidelity: partner is sexually unfaithful.

\begin{tabular}{crlrrrr}
1 & 2 & 3 & 4 & 5 & 6 & 7 \\
Never Happens & & \multicolumn{2}{l}{ Sometimes Happens } & & Happens Repeatedly
\end{tabular}

23. Unacceptable sexual behavior: partner engages in a kind of sexual activity that you find highly unacceptable (with you and/or with other persons).

$\begin{array}{lllllll}1 & 2 & 3 & 4 & 5 & 6 & 7\end{array}$

Never Happens Sometimes Happens Happens Repeatedly

24. In your relationship, you have come to feel that the partner you are with is not the person you thought he or she was at the beginning of the relationship, but is instead a different and lesser person.

$\begin{array}{lllllll}1 & 2 & 3 & 4 & 5 & 6 & 7\end{array}$

I do not feel this way at all I kind of feel this way I strongly feel this way

\section{$\underline{\text { Relationship Satisfaction }}$}

Instructions: In this final section of the questionnaire, we would like to inquire about different aspects of your satisfaction with your relationship.

1. How well does your partner meet your needs?

My partner meets my needs...

$\begin{array}{ccccc}1 & 2 & 3 & 4 & 5 \\ \text { Poorly } & & \text { Average } & & \text { Extremely Well }\end{array}$

2. In general, how satisfied are you with your relationship? 
I am...

$\begin{array}{ccccc}1 & 2 & 3 & 4 & 5 \\ \text { Unsatisfied } & & \text { Average } & & \text { Extremely Satisfied }\end{array}$

3. How good is your relationship compared to most?

My relationship is...

$\begin{array}{ccccc}1 & 2 & 3 & 4 & 5 \\ \text { Poor } & & \text { Average } & & \text { Excellent }\end{array}$

4. How often do you wish you hadn't gotten in this relationship?

I wish I had not gotten in this relationship ...

$\begin{array}{lllll}1 & 2 & 3 & 4 & 5\end{array}$

Never Average Very Often

5. To what extent has your relationship met your original expectations?

My relationship meets my original expectations...

$\begin{array}{lllll}1 & 2 & 3 & 4 & 5\end{array}$

Hardly At All Average Completely

6. How much do you love your partner?

I love my partner...

$\begin{array}{lllll}1 & 2 & 3 & 4 & 5\end{array}$

Not Much Average Very Much

7. I have __ problems in my relationship compared to other couples.

$\begin{array}{ccccc}1 & 2 & 3 & 4 & 5 \\ \text { Very Few } & & \text { Average } & & \text { Very Many }\end{array}$

\section{Relationship Duration}

In months, how long have you been in your current relationship?

\section{Version 2: Fallen out of Love Participants}

[Note: If the participants are randomly assigned to respond to the items based on a previous relationship that they are not currently in, they will be given this version of the survey.] 
Instructions: To begin, please think of a PAST LOVE RELATIONSHIP, which should be one in which you once had a feeling of being in love with your partner, but ceased loving - essentially, fell out of love with - that person over the course of your relationship. Then, keeping this relationship in mind, please respond to the questions regarding how well each description fit or did not fit your relationship with this past partner at the end of your relationship.

PLEASE NOTE: Once you think of a past love relationship, please answer all items on the survey about that particular past relationship. It is important that you try not to switch between different past relationships while answering the items.

\section{$\underline{\text { Relationship Dimensions }}$}

\section{Care for the Partner's Well-being:}

In some relationships, we have a sense that each of us truly cares about the well-being of the other. We have a sense that each of us genuinely cares about, and is willing to make personal efforts when needed, to further the other's welfare and happiness. Such caring may be expressed in many different ways. For example, it might be expressed in a desire to give to the other in ways that will make him or her happy...or in wanting to help and to stand by each other when the other is hurt or ill or unhappy...or in being willing to do things to assist each other in important matters. In all of this, finally, our sense is that each of us is not just giving to get -- are not just doing all of this because there is something in it for us. Rather, each of us is doing it because the welfare and happiness of our partner genuinely matters to us.

To what degree would this description fit...

\begin{tabular}{cllllll}
1 & 2 & 3 & 4 & 5 & 6 & 7 \\
Does Not Fit & \multicolumn{3}{l}{ Somewhat Fits } & & & Fits Very Well
\end{tabular}

1. Your feelings or beliefs towards your partner and the relationship at the end of the relationship

2. Your partner's feelings or beliefs towards you and the relationship at the end of the relationship

\section{Exclusiveness:}

In some relationships, we are exclusive. That is, we regard each other, romantically 
speaking, as our "one and only." We have a sense that we want to have this kind of a relationship only with this partner. We wish to form a sort of "two person community" in which no one else is allowed in romantically-no one else is allowed to relate to us in just the way that this person does. While we may continue friendships and other relationships just as before, there is a specialness to the relationship with our romantic partner which is unique to it and reserved for it only.

To what degree would this description fit...

\begin{tabular}{cllllll}
1 & 2 & 3 & 4 & 5 & 6 & 7 \\
Does Not Fit & \multicolumn{3}{l}{ Somewhat Fits } & & & Fits Very Well
\end{tabular}

1. Your feelings or beliefs towards your partner and the relationship at the end of the relationship

2. Your partner's feelings or beliefs towards you and the relationship at the end of the relationship

\section{Acceptance:}

In some relationships, we have the sense that we are accepted by the other as the person we are. Even though our partner may at times object to certain actions of ours (e.g., to our being late or being messy or driving too fast), we do not get the sense that they want us to be different persons. They do not seem, for example, to want to make us over to be different persons, or to be disappointed that we are not more like some other person they admire. Rather, our sense in the relationship is that we are basically accepted as the person we are.

To what degree would this description fit...

\begin{tabular}{cllllll}
1 & 2 & 3 & 4 & 5 & 6 & 7 \\
Does Not Fit & \multicolumn{3}{l}{ Somewhat Fits } & & & Fits Very Well
\end{tabular}

1. Your feelings or beliefs towards your partner and the relationship at the end of the relationship 
2. Your partner's feelings or beliefs towards you and the relationship at the end of the relationship

\section{Attention Check:}

As an attention check, please select "Does not fit" (or one) for this item. We use this item to identify possible workers who may be randomly responding to the questions. Thank you for your participation and attention so far.

As an attention check, please select "Does not fit" (or one) for this item.

$$
\begin{array}{lllllll}
1 & 2 & 3 & 4 & 5 & 6 & 7
\end{array}
$$

Does Not Fit Somewhat Fits $\quad$ Fits Very Well

\section{Sexual Desire:}

In some relationships, we have strong feelings of sexual desire for each other. We want to be physically intimate with each other -- to touch and be touched, to hold each other in our arms, and to engage in sexual intercouse and/or other sexual acts with each other.

To what degree would this description fit...

\begin{tabular}{cllllll}
1 & 2 & 3 & 4 & 5 & 6 & 7 \\
Does Not Fit & \multicolumn{3}{l}{ Somewhat Fits } & & & Fits Very Well
\end{tabular}

1. Your feelings or beliefs towards your partner and the relationship at the end of the relationship

2. Your partner's feelings or beliefs towards you and the relationship at the end of the relationship

\section{Intimate Confiding in the Other:}

In some relationships, we confide intimately to each other -- we include each other in our intimate worlds. We share with each other what is going on in our lives. We disclose intimate personal experiences and feelings, both positive and negative, to each other. We feel we can really talk to and open up with each other about deeply personal matters.

To what degree would this description fit...

$\begin{array}{lllllll}1 & 2 & 3 & 4 & 5 & 6 & 7\end{array}$


1. Your feelings or beliefs towards your partner and the relationship at the end of the relationship

2. Your partner's feelings or beliefs towards you and the relationship at the end of the relationship

\section{Freedom to be Ourselves:}

In some relationships, we feel free to be ourselves with the other. We do not feel like we have to play any kind of false role with them, or hold back from being the way we really are. We feel like we can just relax and be the person who we really are when we are with them.

To what degree would this description fit...

$\begin{array}{cllllll}1 & 2 & 3 & 4 & 5 & 6 & 7 \\ \text { Does Not Fit } & & \text { Somewhat Fits } & & & \text { Fits Very Well }\end{array}$

1. Your feelings or beliefs towards your partner and the relationship at the end of the relationship

2. Your partner's feelings or beliefs towards you and the relationship at the end of the relationship

\section{Trust:}

In some relationships, we have a basic sense that we can trust each other-that we can count on each other not to to betray us or to violate the relationship that we have. We do not have doubts about very critical matters in our relationship (for example, our partners being sexually unfaithful, lying about significant matters, failing to keep promises, betraying confidences, or hiding important things from us).

To what degree would this description fit...

\begin{tabular}{cllllll}
1 & 2 & 3 & 4 & 5 & 6 & 7 \\
Does Not Fit & \multicolumn{3}{l}{ Somewhat Fits } & & & Fits Very Well
\end{tabular}


1. Your feelings or beliefs towards your partner and the relationship at the end of the relationship

2. Your partner's feelings or beliefs towards you and the relationship at the end of the relationship

\section{Respect:}

In some relationships, we have the sense that each of us respects the other. In other words, we consider each other to be persons who are worthy of esteem and high regard. This respect might be based on a variety of factors. We might, for example, respect each other as caring persons, as morally good persons, as intelligent persons, as capable persons, or for some combination of these and/or other qualities. Whatever the particular reasons might be, however, we find that each of us has a basic respect for the other.

To what degree would this description fit...

\begin{tabular}{cllllll}
1 & 2 & 3 & 4 & 5 & 6 & 7 \\
Does Not Fit & \multicolumn{3}{l}{ Somewhat Fits } & & & Fits Very Well
\end{tabular}

1. Your feelings or beliefs towards your partner and the relationship at the end of the relationship

2. Your partner's feelings or beliefs towards you and the relationship at the end of the relationship

\section{Enjoyment:}

In some relationships, partners enjoy each other. They enjoy being together--enjoy being in each other's company. Even though there may be times of conflict, boredom, or tension in the relationship, for the most part, the experience of being with each other is an enjoyable one.

To what degree would this description fit...

\begin{tabular}{cllllll}
1 & 2 & 3 & 4 & 5 & 6 & 7 \\
Does Not Fit & \multicolumn{3}{l}{ Somewhat Fits } & & & Fits Very Well
\end{tabular}


1. Your feelings or beliefs towards your partner and the relationship at the end of the relationship

2. Your partner's feelings or beliefs towards you and the relationship at the end of the relationship

\section{Knowledge and Understanding:}

In some relationships, we really know and understand each other to a high degree.

Each of us knows things about the other such as his or her deepest values, most cherished goals in life, strengths, weaknesses, vulnerabilities, and interests. As a rule, this knowledge means that we will understand the reasoning and the feelings that are behind each other's actions and reactions, and will not be puzzled or confused by them. For example, if the other is troubled or moody, we are likely to be able to make a good guess as to what is bothering them. We know what "makes each other tick."

To what degree would this description fit...

\begin{tabular}{cllllll}
1 & 2 & 3 & 4 & 5 & 6 & 7 \\
Does Not Fit & \multicolumn{3}{l}{ Somewhat Fits } & & & Fits Very Well
\end{tabular}

1. Your feelings or beliefs towards your partner and the relationship at the end of the relationship

2. Your partner's feelings or beliefs towards you and the relationship at the end of the relationship

\section{Occurrence of Problem Behaviors}

Instructions: In this section of the questionnaire, we would like to inquire about the presence or absence of specific kinds of problem behaviors ON THE PART OF YOUR $\underline{P A R T N E R}$ in your previous relationship, especially in the later stages of your relationship.

1. Negative labeling: partner criticized you by using highly negative labels (e.g., "loser," "narcissist," “crazy," "whore," or other very degrading labels). 


$$
\begin{array}{lllllll}
1 & 2 & 3 & 4 & 5 & 6 & 7
\end{array}
$$

Never Happened Sometimes Happened Happened Repeatedly

2. Defensiveness: in disagreement situations, partner primarily defended himself or herself and did not listen to and truly consider input from you.

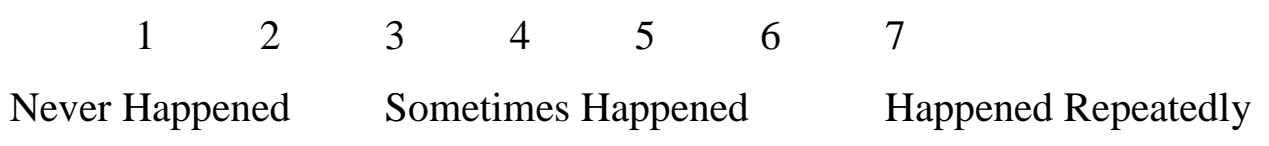

3. Contempt: partner showed contempt for you by such behaviors as ridicule, sarcasm, mocking, laughing at you, putting you down, or in other ways.

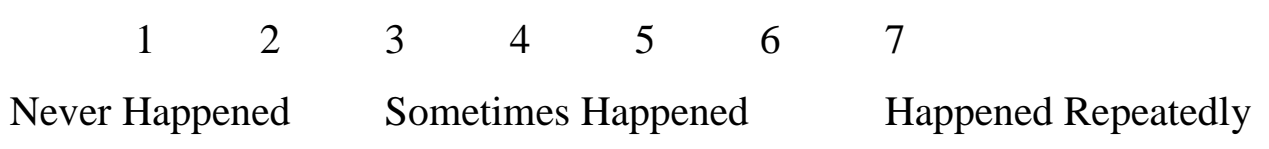

4. Stonewalling: in disagreement situations, partner totally shut you out and refused to listen when you were trying to make your points and express your position (e.g. refused to listen to anything you were saying and/or left the situation).

\begin{tabular}{cclrrrl}
1 & 2 & 3 & 4 & 5 & 6 & 7 \\
Never Happened & & \multicolumn{3}{l}{ Sometimes Happened } & & Happened Repeatedly
\end{tabular}

5. Failure to address issues: partner, though you are pretty sure he or she had some issue with you, kept it to himself or herself and would not talk about it.

$$
\begin{aligned}
& \begin{array}{lllllll}
1 & 2 & 3 & 4 & 5 & 6 & 7
\end{array} \\
& \text { Never Happened Sometimes Happened Happened Repeatedly }
\end{aligned}
$$

6. False agreement: partner pretended to agree with you when you believed s/he didn't really agree (for example, in decision situations, took the position that whatever you wanted was fine with him/her; or, when you thought s/he was actually mad at you about something, didn't admit it and said that everything was fine).

$$
\begin{array}{cclllll}
1 & 2 & 3 & 4 & 5 & 6 & 7 \\
\text { Never Happened } & & \multicolumn{2}{l}{\text { Sometimes Happened }} & & \text { Happened Repeatedly }
\end{array}
$$

7. Attention Check: As an attention check, please select "Happened repeatedly" (or seven) for this item. We use this item to identify possible workers who may be randomly responding to questions. Thank you for your continued participation 
and attention.

$$
\begin{array}{lllllll}
1 & 2 & 3 & 4 & 5 & 6 & 7
\end{array}
$$

Never Happened Sometimes Happened Happened Repeatedly

8. Not sticking to the issue: in disagreement situations, partner did not focus on the issue under discussion, but brought up other things (e.g., negative events from the past, other issues, or comments about your character) that distracted from the present issue.

$\begin{array}{cclrrrr}1 & 2 & 3 & 4 & 5 & 6 & 7 \\ \text { Never Happened } & & \text { Sometimes Happened } & & \text { Happened Repeatedly }\end{array}$

9. Playing for a win: in disagreement situations, partner's primary goal seemed to be to win the argument, not to genuinely consider the merits of what each of you had to say and, based on that, to come to a mutually acceptable solution.

$\begin{array}{lllllll}1 & 2 & 3 & 4 & 5 & 6 & 7\end{array}$

Never Happened Sometimes Happened Happened Repeatedly

10. Physical abuse: partner hit, slapped, pushed, or was otherwise physically abusive to you.

\begin{tabular}{rrrrrrl}
1 & 2 & 3 & 4 & 5 & 6 & 7 \\
Never Happened & & \multicolumn{3}{l}{ Sometimes Happened } & & Happened Repeatedly
\end{tabular}

11. Sexual abuse: partner forced sex upon you, or was otherwise sexually abusive.

\begin{tabular}{cclllll}
1 & 2 & 3 & 4 & 5 & 6 & 7 \\
Never Happened & & \multicolumn{3}{l}{ Sometimes Happened } & & Happened Repeatedly
\end{tabular}

12. Secret-keeping: partner withheld important information from you about matters that affected your relationship.

\begin{tabular}{cclrrrl}
1 & 2 & 3 & 4 & 5 & 6 & 7 \\
Never Happened & & \multicolumn{3}{l}{ Sometimes Happened } & & Happened Repeatedly
\end{tabular}

13. Lying: partner lied to you.

$\begin{array}{cclrrrr}1 & 2 & 3 & 4 & 5 & 6 & 7 \\ \text { Never Happened } & & \text { Sometimes Happened } & & \text { Happened Repeatedly }\end{array}$

14. Taken advantage of: partner used or exploited you for money, sex, or other 
purposes.

$\begin{array}{llllllll}1 & 2 & 3 & 4 & 5 & 6 & 7\end{array}$

Never Happened Sometimes Happened Happened Repeatedly

15. Lack of intimate communication: partner did not open up to you; did not share personal feelings, concerns, or other matters with you.

$\begin{array}{cclllll}1 & 2 & 3 & 4 & 5 & 6 & 7 \\ \text { Never Happens } & & \text { Sometimes Happens } & & & \text { Happens Repeatedly }\end{array}$

16. Pornography use: partner viewed pornography to a degree that you found excessive and harmful to your relationship.

\begin{tabular}{cclrrrl}
1 & 2 & 3 & 4 & 5 & 6 & 7 \\
Never Happened & & \multicolumn{3}{l}{ Sometimes Happened } & & Happened Repeatedly
\end{tabular}

17. Drug use: partner used alcohol or other drugs to a degree that was excessive.$$
\begin{array}{lllllll}
1 & 2 & 3 & 4 & 5 & 6 & 7
\end{array}
$$
Never Happened Sometimes Happened Happened Repeatedly

18. Underfunctioning: partner failed to hold up his or her end of responsibilities in the relationship (e.g., household chores, home maintenance, other).

\begin{tabular}{crlrrrl}
1 & 2 & 3 & 4 & 5 & 6 & 7 \\
Never Happened & & \multicolumn{3}{l}{ Sometimes Happened } & & Happened Repeatedly
\end{tabular}

19. Financial responsibilities: partner failed to hold up his or her end of financial responsibilities in the relationship.

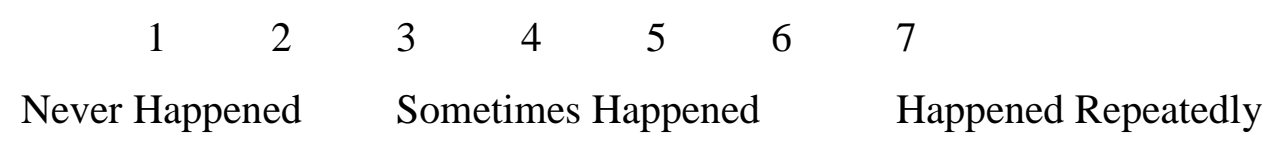

20. Sexual frequency: disagreements between you and your partner about the frequency with which you and your partner desired sex.

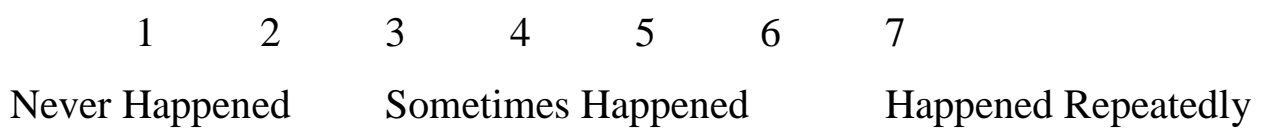

21. Emotional infidelity: partner formed emotional attachments with members of the opposite sex that you felt were overly close and intimate.

$$
\begin{array}{lllllll}
1 & 2 & 3 & 4 & 5 & 6 & 7
\end{array}
$$

Never Happened Sometimes Happened Happened Repeatedly 
22. Sexual infidelity: partner was sexually unfaithful.

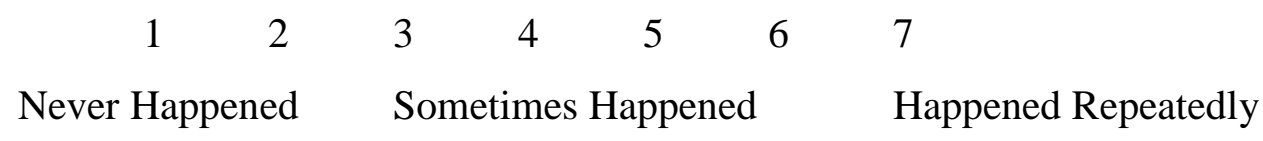

23. Unacceptable sexual behavior: partner engaged in a kind of sexual activity that you found highly unacceptable (with you and/or with other persons).

$\begin{array}{lllllll}1 & 2 & 3 & 4 & 5 & 6 & 7\end{array}$

Never Happened Sometimes Happened Happened Repeatedly

24. In this relationship, you came to feel that the partner you were with was not the person you thought he or she was at the beginning of the relationship, but was instead a different and lesser person.

$$
\begin{array}{lllllll}
1 & 2 & 3 & 4 & 5 & 6 & 7
\end{array}
$$

I did not feel this way at all I kind of felt this way I strongly felt this way

\section{Relationship Satisfaction}

Instructions: In this final section of the questionnaire, we would like to inquire about different aspects of satisfaction with your previous partner, especially in the later stages of your relationship.

1. How well did this partner meet your needs?

This partner met my needs...

$\begin{array}{ccccc}1 & 2 & 3 & 4 & 5 \\ \text { Poorly } & & \text { Average } & & \text { Extremely Well }\end{array}$

2. In general, how satisfied were you with this relationship?

I was...

$\begin{array}{ccccc}1 & 2 & 3 & 4 & 5 \\ \text { Unsatisfied } & & \text { Average } & & \text { Extremely Satisfied }\end{array}$

3. How good was this relationship compared to most?

This relationship was...

$\begin{array}{ccccc}1 & 2 & 3 & 4 & 5 \\ \text { Poor } & & \text { Average } & & \text { Excellent }\end{array}$

4. How often did you wish you hadn't gotten in this relationship? 
I wished I had not gotten in this relationship...

$\begin{array}{lllll}1 & 2 & 3 & 4 & 5\end{array}$

Never

Average

Very Often

5. To what extent had this relationship met your original expectations?

This relationship met my original expectations...

$\begin{array}{ccccc}1 & 2 & 3 & 4 & 5 \\ \text { Hardly At All } & \text { Average } & & \text { Completely }\end{array}$

6. How much did you love this partner?

I loved this partner...

$\begin{array}{ccccc}1 & 2 & 3 & 4 & 5 \\ \text { Not Much } & & \text { Average } & & \text { Very Much }\end{array}$

7. I had problems in this relationship compared to other couples.

$\begin{array}{ccccc}1 & 2 & 3 & 4 & 5 \\ \text { Very Few } & & \text { Average } & & \text { Very Many }\end{array}$

\section{$\underline{\text { Relationship Duration }}$}

In months, how long were you in this previous relationship? 